\title{
A general class of noninstantaneous impulsive fractional differential inclusions in Banach spaces
}

\author{
JinRong Wang ${ }^{1}$, AG Ibrahim² , D O'Regan ${ }^{3}$ and Yong Zhou ${ }^{4,5^{*}}$
}

\section{"Correspondence:}

yzhou@xtu.edu.cn

${ }^{4}$ Faculty of Mathematics and

Computational Science, Xiangtan

University, Hunan, 411105, P.R. China

${ }^{5}$ Nonlinear Analysis and Applied

Mathematics (NAAM) Research

Group, Faculty of Science, King

Abdulaziz University, P.O. Box 80203,

Jeddah, 21589, Saudi Arabia

Full list of author information is

available at the end of the article

\begin{abstract}
In this paper we introduce the concept of a PC-mild solution to a general new class of noninstantaneous impulsive fractional differential inclusions involving the generalized Caputo derivative with the lower bound at zero in infinite dimensional Banach spaces. Using the formula of a PC-mild solution, we give two classes of sufficient conditions to guarantee the existence of $\mathrm{PC}$-mild solutions via fixed point theorems for multivalued functions. Also we characterize the compactness of the solution set. We introduce the concept of generalized Ulam-Hyers stability and present a generalized Ulam-Hyers stability result using multivalued weakly Picard operator theory. Examples are given to illustrate the theoretical results.
\end{abstract}

MSC: 26A33; 34A60

Keywords: noninstantaneous impulsive; fractional differential inclusions; multivalued functions; measure of noncompactness; compactness of solutions set; Ulam-Hyers stability

\section{Introduction}

Fractional inequalities, equations and inclusions arise in various fields, such as physics, mechanics and engineering [1-8] and in particular fractional differential inclusions arise in mathematical modelling of problems in game theory, stability and optimal control. For some recent development on qualitative analysis of fractional differential equations and inclusions, we refer the reader to [9-20] and the references therein.

The theory of impulsive differential equations and impulsive differential inclusions arises naturally in biology, physics, engineering, and medical fields [21-24] and model processes where at certain moments they change their state rapidly. In general, there are two impulsive effect in differential equations. One is called instantaneous impulsive differential equations (see [25], i.e., the duration of these changes is relatively short compared to the overall duration of the whole process). The other is noninstantaneous impulsive differential equations (see [26], i.e., the impulsive action starts at an arbitrary fixed point and remains active on a finite time interval). For developments in the study of mild solutions to instantaneous impulsive differential equations we refer the reader to [27-31] and the references therein. However, the action of instantaneous impulses does not describe some dynamics of evolution processes in pharmacotherapy. Consider the hemodynamic

(c) The Author(s) 2017. This article is distributed under the terms of the Creative Commons Attribution 4.0 International License (http://creativecommons.org/licenses/by/4.0/), which permits unrestricted use, distribution, and reproduction in any medium, provided you give appropriate credit to the original author(s) and the source, provide a link to the Creative Commons license, and indicate if changes were made. 
equilibrium of a person. In the case of a decompensation, for example high or low levels of glucose, one can prescribe some intravenous drugs insulin. The introduction of the drugs in the bloodstream and the consequent absorption for the body are gradual and continuous process. In this situation the impulsive action starts at any arbitrary fixed point and stays active on a finite time interval. Hernándaz and O’Regan [26] introduced a new class of noninstantaneous impulsive differential equations of the form

$$
\left\{\begin{array}{l}
x^{\prime}(t)=A x(t)+f(t, x(t)), \quad t \in\left(s_{i}, t_{i+1}\right], i=0,1,2, \ldots, m, \\
x(t)=g_{i}(t, x(t)), \quad t \in\left(t_{i}, s_{i}\right], i=1,2, \ldots, m, \\
x(0)=x_{0}
\end{array}\right.
$$

where $A: D(A) \subseteq E \rightarrow E$ is the generator of a $C_{0}$-semigroup $\{T(t): t \geq 0\}$ on a Banach space $E$ with a norm $\|\cdot\|, f:[0, b] \times E \rightarrow E$ is a given function, and the fixed points $s_{i}$ and $t_{i}$ satisfy $0=s_{0}<t_{1} \leq s_{1}<t_{2} \leq s_{2}<t_{3} \cdots<t_{m} \leq s_{m}<t_{m+1}=b$, and $g_{i}:\left[t_{i}, s_{i}\right] \times E \rightarrow E$ is continuous for all $i=1,2, \ldots, m$. Pierri et al. [32] studied the existence and uniqueness of (1) in the fractional power space using the theory of analytic semigroups. Motivated by [26], Wang and Fečkan [33] modified (1) to the following form:

$$
\left\{\begin{array}{l}
x^{\prime}(t)=A x(t)+f(t, x(t)), \quad t \in\left(s_{i}, t_{i+1}\right), i=0,1,2, \ldots, m, \\
x\left(t_{i}^{+}\right)=g_{i}\left(t_{i}, x\left(t_{i}^{-}\right)\right), \quad i=1,2, \ldots, m, \\
x(t)=g_{i}\left(t, x\left(t_{i}^{-}\right)\right), \quad t \in\left(t_{i}, s_{i}\right], i=1,2, \ldots, m, \\
x(0)=x_{0}
\end{array}\right.
$$

where $x\left(t_{i}^{-}\right)$and $x\left(t_{i}^{+}\right)$are the left and right limit, respectively, of the function $x$ at the points $t_{i}, i=1, \ldots, m$, and an existence uniqueness result for (2) was presented. For recent work on this topic we refer the reader to [34-41] and the references therein.

For the theory of Ulam stability [42] we refer the reader to [43-50]. Wang and Fečkan [33] introduced four types of Ulam stability for (2) and presented generalized Ulam-HyersRassias stability results for (2) on both compact and unbounded intervals.

For impulsive fractional differential equations, one can propose different concepts of solutions. There are basically two approaches in the literature, one by adopting a generalized Caputo derivative keeping the lower bound at zero and the other using the classical Caputo derivative and switching it at the impulsive points. In this paper, we study existence and stability of noninstantaneous impulsive fractional differential inclusions of the form

$$
\left\{\begin{array}{l}
{ }^{c} D_{0, t}^{\alpha} x(t) \in F(t, x(t)) \quad \text { a.e. } t \in\left(s_{i}, t_{i+1}\right], i=0,1, \ldots, m, \alpha \in(0,1), \\
x\left(t_{i}^{+}\right)=g_{i}\left(t_{i}, x\left(t_{i}^{-}\right)\right), \quad i=1, \ldots, m, \\
x(t)=g_{i}\left(t, x\left(t_{i}^{-}\right)\right), \quad t \in\left(t_{i} s_{i}\right], i=1, \ldots, m, \\
x(0)=x_{0},
\end{array}\right.
$$

in a separable Banach space $E$, where ${ }^{c} D_{0, t}^{\alpha} x(t)$ is the generalized Caputo derivative which is defined via the Riemann-Liouville fractional derivative of order $\alpha$ with the lower limit zero for the function $x$ at the point $t$, and the multifunction $F:[0, b] \times E \rightarrow 2^{E}$ will be defined later. 
The main contributions are:

(i) We give a concept of PC-mild solutions to (3).

(ii) Using fixed point theorems for multivalued functions we obtain two classes of sufficient conditions to guarantee existence of PC-mild solutions in piecewise continuous spaces endowed with the Chebyshev norm and the Bielecki norm. In addition, the compactness of the solution set is also discussed.

(iii) We introduce a concept of generalized Ulam-Hyers stability for noninstantaneous impulsive fractional differential inclusions and we present a generalized-Ulam-Hyers stability result using multivalued weakly Picard operator theory.

\section{Preliminaries and notations}

Let $J=[0, b]$. Denote $P_{b}(E)=\{B \subseteq E: B$ is non-empty and bounded $\}, P_{c l}(E)=\{B \subseteq E$ : $B$ is non-empty, convex and closed $\}, \quad P_{c k}(E)=\{B \subseteq E:$ Bis non-empty, convex and compact\}, and let $\operatorname{conv}(B)$ (respectively, $\overline{\operatorname{conv}}(B)$ ) be the convex hull (respectively, convex closed hull in $E$ of a subset $B$. Let $L^{p}(J, E)$ be the space of $E$-valued Bochner integrable functions on $J$ with the norm $\|f\|_{L^{p}(J, E)}=\left(\int_{0}^{b}\|f(t)\|^{p} d t\right)^{\frac{1}{p}}$. We recall that, [51] if $X$ and $Y$ are two topological spaces, then a multifunction $G: X \rightarrow P(Y)$ is said to be upper semicontinuous (u.s.c.) if $G^{-1}(V)=\{x \in X: G(x) \subseteq V\}$ is an open subset of $X$ for every open $V \subseteq Y$. Also $G$ is called closed if its graph $\Gamma_{G}=\{(x, y) \in X \times Y: y \in G(x)\}$ is closed subset of the topological space $X \times Y$ and $G$ is said to be completely continuous if $G(B)$ is relatively compact for every bounded subset $B$ of $X$.

If $X$ and $Y$ are two Hausdorff topological spaces and $G: X \rightarrow P(Y)$ is a u.s.c. multifunction with non-empty closed values, then it is closed, and if $Y$ is compact and $G$ is closed, then it is u.s.c.

If $X$ is a normed space and $G: J \rightarrow P_{c l}(X)$, then the set $S_{G}^{p}=\left\{f \in L^{p}(J, X): f(t) \in\right.$ $G(t)$, a.e. $t \in J\}$ is called the set of Lebesgue $p$-integrable selections of $G$.

To introduce the concept of mild solution of (3), we consider the set of functions

$$
\begin{aligned}
\operatorname{PC}(J, E)= & \left\{x: J \rightarrow E: x_{\mid J_{i}} \in C\left(J_{i}, E\right), J_{i}=\left(s_{i}, t_{i+1}\right], i=0,1, \ldots, m,\right. \text { and } \\
& \left.x\left(t_{i}^{+}\right) \text {and } x\left(t_{i}^{-}\right) \text {exist for each } i=1, \ldots, m\right\},
\end{aligned}
$$

where $x_{I_{i}}$ denotes the domain of $x$ restricted to the subinterval $J_{i} \subset J$.

It is well known that $\mathrm{PC}(J, E)$ is a Banach space endowed with the Chebyshev $\mathrm{PC}$-norm:

$$
\|x\|_{\mathrm{PC}(J, E)}=\max \{\|x(t)\|: t \in J\},
$$

or the Bielecki PCB-norm:

$$
\|x\|_{\mathrm{PCB}(J, E)}=\max \left\{e^{-L t}\|x(t)\|: t \in J\right\}, \quad L \in[0, \infty) .
$$

Next, we consider the map $\chi_{\mathrm{PC}}: P_{b}(\mathrm{PC}(J, E)) \rightarrow[0, \infty]$ defined by

$$
\chi_{\mathrm{PC}}(B)=\max _{i=0,1, \ldots, m} \chi_{i}\left(B_{\mid \overline{J_{i}}}\right)
$$


where $\chi_{i}, i=0,1, \ldots, m$, is the Hausdorff measure of noncompactness on the Banach space $C\left(\overline{J_{i}}, E\right)$ and

$$
B_{\bar{J}_{i}}=\left\{x^{*}: \bar{J}_{i} \rightarrow E: x^{*}(t)=x(t), t \in J_{i} \text { and } x^{*}\left(t_{i}\right)=x\left(t_{i}^{+}\right), x \in B\right\} .
$$

Of course $B_{\mid \overline{J_{0}}}=\left\{x_{\mid \bar{J}_{0}}: x \in B\right\}$. It is easily seen that $\chi_{\mathrm{PC}}$ is the Hausdorff measure of noncompactness on the Banach space $\mathrm{PC}(J, E)$.

In what follows, we recall some basic concepts and properties of fractional calculus in $[52,53]$.

Definition 2.1 (see [52], p.10, (1.9)) The Riemann-Liouville fractional integral of order $q>0$ with the lower limit zero for a function $f \in L^{p}(J, E), p \in[1, \infty)$ is defined as follows:

$$
I_{0, t}^{q} f(t)=\left(g_{q} * f\right)(t)=\int_{0}^{t} \frac{(t-s)^{q-1}}{\Gamma(q)} f(s) d s, \quad t \in J,
$$

where $g_{q}(t)=\frac{t^{q-1}}{\Gamma(q)}$, for $t>0$ and $g_{q}(t)=0$ for $t \leq 0$, the symbol $*$ denotes the convolution of function and $\Gamma(\cdot)$ is the Euler Gamma function defined by $\Gamma(q)=\int_{0}^{\infty} t^{q-1} e^{-t} d t$ and the integration is understand in the sense of Bochner. Obviously, $I_{0, t}^{0} f(t)=f(t)$ for $q=0$.

It is well known [52], p.10, (1.10), that

$$
I_{0, t}^{q} I_{0, t}^{\beta} f(t)=I_{0, t}^{q+\beta} f(t), \quad \beta, q \geq 0 .
$$

Moreover, by applying Young's inequality, it follows that

$$
\left\|I_{0, t}^{q} f\right\|_{L^{p}(J, E)}=\left\|g_{q} * f\right\|_{L^{p}(J, E)} \leq\left\|g_{q}\right\|_{L^{1}\left(J, \mathbb{R}^{+}\right)}\|f\|_{L^{p}(J, E)}=g_{q+1}(b)\|f\|_{L^{p}(J, E)} .
$$

Then $I_{0, t}^{q}$ maps $L^{p}(J, E)$ to $L^{p}(J, E)$.

Definition 2.2 ([52], p.10, (1.11)) Let $q>0, m$ be the smallest integer greater than or equal to $q$ and $f \in L^{1}(J, E)$ such that $g_{m-q} * f \in W^{m, 1}(J, E)$. The Riemann-Liouville fractional derivative of order $q$ with the lower limit zero for $f$ is defined by

$$
D_{0, t}^{q} f(t)=\frac{d^{m}}{d t^{m}} I_{0, t}^{m-q} f(t)=\frac{d^{m}}{d t^{m}}\left(g_{m-q} * f\right)(t)
$$

where

$$
W^{m, 1}(J, E)=\left\{f: f(t)=\sum_{k=0}^{m-1} c_{k} \frac{t^{k}}{k !}+I^{m} \varphi(t), t \in J \text { for some } \varphi \in L^{1}(J, E)\right\} .
$$

Note that in the above definition $\varphi=f^{(m)}$ and $c_{k}=f^{(k)}(0), k=0,1, \ldots, m-1$.

Next, we collect some elementary properties for Riemann-Liouville fractional integral and derivative.

Lemma 2.3 (see [53], p.74, Prop. 2.2) Let $q>0$ and $m$ be the smallest integer greater than or equal to $q$. Then we have 
(i) If $f \in L^{1}(J, E)$, then $g_{m-q} *\left(I_{0, t}^{q} f\right) \in W^{m, 1}(J, E)$ and $D_{0, t}^{q} I_{0, t}^{q} f(t)=f(t)$ a.e.

(ii) If $\gamma>q$ and $f \in L^{1}(J, E)$ then $D_{0, t}^{q} I_{0, t}^{\gamma} f(t)=I_{0, t}^{\gamma-q} f(t)$ a.e. In particular, if $\gamma>k, k \in \mathbb{N}$, then $D_{0, t}^{k} I^{\gamma} f(t)=I_{0, t}^{\gamma-k} f(t)$ a.e.

(iii) If $p>\frac{1}{q}$ and $f \in L^{1}(J, E)$, then $I_{0, t}^{q} f(t)$ is continuous.

Definition 2.4 ([52], p.10, (1.20)) Let $q>0$ and $m$ be an integer such that $m-1<q<m$. The Caputo derivative of order $q$ with the lower limit zero for a given function $f \in L^{1}(J, E)$ is defined by

$$
{ }^{c} D_{0, t}^{q} f(t)=D_{0, t}^{q}\left(f(t)-\sum_{k=0}^{m-1} \frac{f^{(k)}(0)}{k !} t^{k}\right),
$$

provided the right side is point-wise defined on $J$.

We have the following:

(i) If $f \in C^{(m)}(J, E)$, then

$$
{ }^{c} D_{0, t}^{q} f(t)=\frac{1}{\Gamma(m-q)} \int_{0}^{t}(t-s)^{m-q-1} f^{(n)}(s) d s .
$$

(ii) If $f \in L^{p}(J, E), p>\frac{1}{q}$, then $\left(I_{0, t}^{q} f\right)^{(k)}(t), k=1, \ldots, m-1$ exists at any $t \in J$ and

$$
\begin{aligned}
& \left(I_{0, t}^{q} f\right)^{(k)}(0)=0, k=1, \ldots, m-1, \text { so } \\
& \quad{ }^{c} D_{0, t}^{q} I_{0, t}^{q} f(t)=D_{0, t}^{q} I_{0, t}^{q} f(t)=f(t), \quad \text { a.e. } t \in J .
\end{aligned}
$$

Lemma 2.5 Let $\alpha \in(0,1)$, and $h \in L^{p}(J, E), p>\frac{1}{\alpha}$. Assume $x: J \rightarrow E$ be a function defined by

$$
x(t)=\left\{\begin{array}{l}
x_{0}+\frac{1}{\Gamma(\alpha)} \int_{0}^{t}(t-s)^{\alpha-1} h(s) d s, \quad t \in\left[0, t_{1}\right], \\
g_{i}\left(t, x\left(t_{i}^{-}\right)\right), \quad t \in\left(t_{i}, s_{i}\right], i=1,2, \ldots, m, \\
g_{i}\left(s_{i}, x\left(t_{i}^{-}\right)\right)-\frac{1}{\Gamma(\alpha)} \int_{0}^{s_{i}}\left(s_{i}-s\right)^{\alpha-1} h(s) d s \\
\quad+\frac{1}{\Gamma(\alpha)} \int_{0}^{t}(t-s)^{\alpha-1} h(s) d s, \quad t \in\left[s_{i}, t_{i+1}\right], i=1,2, \ldots, m .
\end{array}\right.
$$

Then we have the following results:

(i) The function $x$ has the Caputo derivative of order $\alpha$ on $\left(s_{i}, t_{i+1}\right], i=0,1, \ldots, m$, and satisfies the following linear problems:

$$
\left\{\begin{array}{l}
{ }^{c} D_{0, t}^{\alpha} x(t)=h(t) \quad \text { a.e. } t \in\left(s_{i}, t_{i+1}\right], i=0,1, \ldots, m \\
x\left(t_{i}^{+}\right)=g_{i}\left(t_{i}, x\left(t_{i}^{-}\right)\right), \quad i=1, \ldots, m \\
x(t)=g_{i}\left(t, x\left(t_{i}^{-}\right)\right), \quad t \in\left(t_{i}, s_{i}\right], i=1, \ldots, m \\
x(0)=x_{0}
\end{array}\right.
$$

(ii) The function $x$ is continuous at $s_{i}, i=1, \ldots, m$.

(iii) If $t_{i}=s_{i}, g_{i}(t, x)=x, i=1, \ldots, m$ and $(t, x) \in J \times E$, then

$$
x\left(t_{i}^{-}\right)=x\left(t_{i}^{+}\right), \quad i=1, \ldots, m,
$$


and for any $t \in J$,

$$
x(t)=x_{0}+\frac{1}{\Gamma(\alpha)} \int_{0}^{t}(t-s)^{\alpha-1} h(s) d s .
$$

Proof (i) Let $t \in\left(s_{i}, t_{i+1}\right], i=0,1, \ldots, m$. Using Lemma 2.3(ii) and (4) we have

$$
{ }^{c} D_{0, t}^{\alpha} x(t)={ }^{c} D_{0, t}^{\alpha} I_{0, t}^{\alpha} h(t)=h(t) \text { a.e. }
$$

(ii) For any $i=1, \ldots, m$,

$$
\begin{aligned}
\lim _{t \rightarrow s_{i}^{+}} x(t)= & \lim _{t \rightarrow s_{i}^{+}}\left[g_{i}\left(s_{i}, x\left(t_{i}^{-}\right)\right)-\frac{1}{\Gamma(\alpha)} \int_{0}^{s_{i}}\left(s_{i}-s\right)^{\alpha-1} h(s) d s\right. \\
& \left.+\frac{1}{\Gamma(\alpha)} \int_{0}^{t}(t-s)^{\alpha-1} h(s) d s\right] \\
= & g_{i}\left(s_{i}, x\left(t_{i}^{-}\right)\right)=x\left(s_{i}^{-}\right) .
\end{aligned}
$$

(iii) Assume that $t_{i}=s_{i}, g_{i}(t, x)=x, i=1, \ldots, m$ and $(t, x) \in J \times E$. Note that

$$
x\left(t_{i}^{+}\right)=g_{i}\left(t_{i}, x\left(t_{i}^{-}\right)\right)=x\left(t_{i}^{-}\right) .
$$

Moreover, for $t \in\left(t_{1}, t_{2}\right]$,

$$
\begin{aligned}
x(t)= & x\left(t_{1}^{-}\right)-\frac{1}{\Gamma(\alpha)} \int_{0}^{t_{1}}\left(t_{1}-s\right)^{\alpha-1} h(s) d s+\frac{1}{\Gamma(\alpha)} \int_{0}^{t}(t-s)^{\alpha-1} h(s) d s \\
= & x_{0}+\frac{1}{\Gamma(\alpha)} \int_{0}^{t_{1}}\left(t_{1}-s\right)^{\alpha-1} h(s) d s-\frac{1}{\Gamma(\alpha)} \int_{0}^{t_{1}}\left(t_{1}-s\right)^{\alpha-1} h(s) d s \\
& +\frac{1}{\Gamma(\alpha)} \int_{0}^{t}(t-s)^{\alpha-1} h(s) d s \\
= & x_{0}+\frac{1}{\Gamma(\alpha)} \int_{0}^{t}(t-s)^{\alpha-1} h(s) d s .
\end{aligned}
$$

Similarly, for $t \in\left(t_{2}, t_{3}\right]$,

$$
\begin{aligned}
x(t)= & x\left(t_{2}^{-}\right)-\frac{1}{\Gamma(\alpha)} \int_{0}^{t_{2}}\left(t_{2}-s\right)^{\alpha-1} h(s) d s+\frac{1}{\Gamma(\alpha)} \int_{0}^{t}(t-s)^{\alpha-1} h(s) d s \\
= & x_{0}+\frac{1}{\Gamma(\alpha)} \int_{0}^{t_{2}}\left(t_{2}-s\right)^{\alpha-1} h(s) d s-\frac{1}{\Gamma(\alpha)} \int_{0}^{t_{2}}\left(t_{2}-s\right)^{\alpha-1} h(s) d s \\
& +\frac{1}{\Gamma(\alpha)} \int_{0}^{t}(t-s)^{\alpha-1} h(s) d s \\
= & x_{0}+\frac{1}{\Gamma(\alpha)} \int_{0}^{t}(t-s)^{\alpha-1} h(s) d s .
\end{aligned}
$$

Next, one can repeat the above procedure to obtain

$$
x(t)=x_{0}+\frac{1}{\Gamma(\alpha)} \int_{0}^{t}(t-s)^{\alpha-1} h(s) d s, \quad \forall t \in J .
$$

The proof is complete. 
Lemma 2.6 Assume that $E$ is a reflexive Banach space and $\alpha \in(0,1)$. If $x \in C^{1}(J, E)$ then

$$
I_{0, t}^{\alpha}\left({ }^{c} D_{0, t}^{\alpha} x(t)\right)=x(t)-x(0), \quad \forall t \in J .
$$

Proof Since $E$ is reflexive Banach space and $x \in C^{1}(J, E)$, then there is a $h \in L^{1}(J, E)$ such that

$$
x(t)=x(0)+\int_{0}^{t} h(s) d s, \quad \forall t \in J .
$$

Then

$$
I_{0, t}^{\alpha}\left({ }^{c} D_{0, t}^{\alpha} x(t)\right)=I_{0, t}^{\alpha}\left(I_{0, t}^{1-\alpha} x^{(1)}(t)\right)=I_{0, t}\left(x^{(1)}(t)\right)=x(t)-x(0) .
$$

The proof is finished.

Lemma 2.7 Assume that $E$ is a reflexive Banach space. Let $\alpha \in(0,1)$ and $h \in L^{1}(J$,E). If $x \in \operatorname{PC}(J, E) \bigcap_{i=0}^{i=m} C^{1}\left(\left(s_{i}, t_{i+1}\right), E\right)$ and satisfies (6), then $x$ satisfies (5).

Proof Let $t \in\left[0, t_{1}\right]$ such that ${ }^{c} D_{0, t}^{\alpha} x(t)=h(t)$. Then

$$
I_{0, t}^{\alpha} h(t)=I_{0, t}^{\alpha}\left({ }^{c} D_{0, t}^{\alpha} x(t)\right)=x(t)+c_{0} .
$$

Since $x(0)=x_{0}$,

$$
x(t)=x_{0}+\frac{1}{\Gamma(\alpha)} \int_{0}^{t}(t-s)^{\alpha-1} h(s) d s, \quad \text { for } t \in\left[0, t_{1}\right] .
$$

Let $t \in\left(s_{1}, t_{2}\right)$ such that ${ }^{c} D_{0, t}^{\alpha} x(t)=h(t)$. Then

$$
I_{0, t}^{\alpha} h(t)=I_{0, t}^{\alpha}\left({ }^{c} D_{0, t}^{\alpha} x(t)\right)=x(t)+c_{1} .
$$

Thus,

$$
x(t)=I_{0, t}^{\alpha} h(t)-c_{1} .
$$

Note that $x\left(s_{1}^{-}\right)=g_{1}\left(s_{1}^{-}, x\left(t_{1}^{-}\right)\right)$, and we have

$$
c_{1}=g_{1}\left(s_{1}^{-}, x\left(t_{1}^{-}\right)\right)-I_{0, s_{1}}^{\alpha} h(t)
$$

Thus, for $t \in\left(s_{1}, t_{2}\right)$

$$
\begin{aligned}
x(t) & =g_{1}\left(s_{1}^{-}, x\left(t_{1}^{-}\right)\right)-I_{0, s_{1}}^{\alpha} h(t)+\frac{1}{\Gamma(\alpha)} \int_{0}^{t}(t-s)^{\alpha-1} h(s) d s \\
& =g_{1}\left(s_{1}^{-}, x\left(t_{1}^{-}\right)\right)-\frac{1}{\Gamma(\alpha)} \int_{0}^{s_{1}}\left(s_{1}-s\right)^{\alpha-1} h(s) d s+\frac{1}{\Gamma(\alpha)} \int_{0}^{t}(t-s)^{\alpha-1} h(s) d s .
\end{aligned}
$$

Similarly, we can show that $x$ satisfies (5) for the other subintervals.

Now, we introduce the concept of a mild solution for problem (3). 
Definition 2.8 A function $x \in \mathrm{PC}(J, E)$ is called a PC-mild solution of (3) if

$$
x(t)=\left\{\begin{array}{l}
x_{0}+\frac{1}{\Gamma(\alpha)} \int_{0}^{t}(t-s)^{\alpha-1} f(s) d s, \quad t \in\left[0, t_{1}\right], \\
g_{i}\left(t, x\left(t_{i}^{-}\right)\right), \quad t \in\left(t_{i}, s_{i}\right], i=1,2, \ldots, m, \\
g_{i}\left(s_{i}, x\left(t_{i}^{-}\right)\right)-\frac{1}{\Gamma(\alpha)} \int_{0}^{s_{i}}\left(s_{i}-s\right)^{\alpha-1} f(s) d s \\
\quad+\frac{1}{\Gamma(\alpha)} \int_{0}^{t}(t-s)^{\alpha-1} f(s) d s, \quad t \in\left(s_{i}, t_{i+1}\right], i=1,2, \ldots, m,
\end{array}\right.
$$

where $f \in S_{F(\cdot, x(\cdot))}^{p}$

We need the following lemma.

Lemma 2.9 ([54], p.65, p.88, Theorem III.41) Let $(T, \beta)$ be a measurable space and $(E, d)$ a separable Banach space. Let $G: T \rightarrow 2^{E}$ be a measurable closed valued multifunction and $g: T \rightarrow E$ be a measurable function. If the multivalued function

$$
U(t)=\{x \in G(t):\|g(t)-x\|=d(g(t), G(t))\},
$$

has non-empty values, then there is a measurable function $z: T \rightarrow E$ such that $z(t) \in U(t)$ a.e., i.e.,

$$
\|g(t)-z(t)\|=d(g(t), G(t)), \quad \text { a.e. }
$$

The following fixed point theorems are crucial in the proof of our main result.

Lemma 2.10 (see [55], p.583, Cor. 17.55 or [56]) (Kakutani-Fan-Glicksberg) Let W be a non-empty compact and convex subset of a locally convex topological vector space. If $R: W \rightarrow P_{c l, c v}(W)$ is an u.s.c. multifunction, then it has a fixed point.

Lemma 2.11 (see [56], p.77, Prop. 3.5.1) Let $W$ be a closed subset of a Banach space $X$ and $R: W \rightarrow P_{c k}(X)$ be a closed multifunction which is $\gamma$-condensing on every bounded subset of $W$, where $\gamma$ is a monotone measure of noncompactness defined on $X$. If the set of fixed points for $R$ is a bounded subset of $X$ then it is compact.

Lemma 2.12 (see [57], p.6) Let $(X, d)$ be a complete metric space. If $R: X \rightarrow P_{c l}(X)$ is a contraction, then $R$ has a fixed point.

\section{Existence of mild solutions for the problem (3)}

In this section, we establish existence results for mild solutions of (3).

Theorem 3.1 Let $F: J \times E \rightarrow P_{c k}(E)$ be a multifunction and $g_{i}:\left[t_{i}, s_{i}\right] \times E \rightarrow E, i=$ $1,2, \ldots, m$. We assume the following conditions:

$\left(H_{1}\right)$ For every $x \in E, t \rightarrow F(t, x)$ is measurable and for a.e. $t \in J, x \rightarrow F(t, x)$ is upper semicontinuous.

$\left(H_{2}\right)$ There exist a function $\varphi \in L^{p}\left(J, \mathbb{R}^{+}\right), p>\frac{1}{\alpha}$, and a nondecreasing continuous function $\Omega:[0, \infty) \rightarrow[0, \infty]$ such that, for any $x \in E$,

$$
\|F(t, x)\| \leq \varphi(t) \Omega(\|x\|), \quad \text { a.e. } t \in J
$$


$\left(H_{3}\right)$ There exists a function $\beta \in L^{p}\left(J, \mathbb{R}^{+}\right), p>\frac{1}{\alpha}$, satisfying

$$
8 \eta\|\beta\|_{L^{p}\left(, \mathbb{R}^{+}\right)}<1
$$

and for every bounded subset $D \subseteq E$,

$$
\chi(F(t, D)) \leq \beta(t) \chi(D) \quad \text { for a.e. } t \in J
$$

where $\chi$ is the Hausdorff measure of noncompactness in $E$ and $\eta=\frac{b^{\alpha-\frac{1}{p}}}{\Gamma(\alpha)}\left(\frac{p-1}{\alpha p-1}\right)^{\frac{p-1}{p}}$.

$\left(H_{4}\right)$ For every $i=1,2, \ldots, m, g_{i}$ is continuous and completely continuous and there exists a positive constant $h_{i}$ such that

$$
\left\|g_{i}(t, x)\right\| \leq h_{i}\|x\|, \quad t \in\left[t_{i}, s_{i}\right], x \in E .
$$

Then problem (3) has a PC-mild solution provided that there is a $r>0$ such that

$$
\left\|x_{0}\right\|+\bar{h} r+2 \Omega(r) \eta\|\varphi\|_{L^{p}\left(J, \mathbb{R}^{+}\right)} \leq r
$$

where $\bar{h}=\sum_{i=1}^{m} h_{i}$.

Proof From $\left(H_{1}\right)$ and $\left(H_{2}\right), S_{F(\cdot, x(\cdot))}^{p}$ is non-empty (see [56]). Now we turn problem (3) into a fixed point problem and define a multifunction $R: \mathrm{PC}(J, E) \rightarrow 2^{\mathrm{PC}(J, E)}$ as follows: for $x \in \mathrm{PC}(J, E), R(x)$ is the set of all functions $y \in R(x)$ such that

$$
y(t)=\left\{\begin{array}{l}
x_{0}+\frac{1}{\Gamma(\alpha)} \int_{0}^{t}(t-s)^{\alpha-1} f(s) d s, \quad t \in\left[0, t_{1}\right] \\
g_{i}\left(t, x\left(t_{i}^{-}\right)\right), \quad t \in\left(t_{i}, s_{i}\right], i=1,2, \ldots, m, \\
g_{i}\left(s_{i}, x\left(t_{i}^{-}\right)\right)-\frac{1}{\Gamma(\alpha)} \int_{0}^{s_{i}}\left(s_{i}-s\right)^{\alpha-1} f(s) d s \\
\quad+\frac{1}{\Gamma(\alpha)} \int_{0}^{t}(t-s)^{\alpha-1} f(s) d s, \quad t \in\left[s_{i}, t_{i+1}\right], i=1,2, \ldots, m,
\end{array}\right.
$$

where $f \in S_{F(\cdot, x(\cdot))}^{p}$.

It is easy to see that any fixed point for $R$ is a mild solution for (3). We prove using Lemma 2.10 that $R$ has a fixed point.

Let $B_{0}=\{x \in \mathrm{PC}(J, E):\|x\| \leq r\}$. Note $B_{0}$ is a bounded, closed and convex subset of $\mathrm{PC}(J, E)$. Now, we claim that $R\left(B_{0}\right) \subseteq B_{0}$. To prove this, let $x \in B_{0}$ and $y \in R(x)$. Using $\left(H_{2}\right)$, (9), (10) and Hölder's inequality we get for $t \in\left[0, t_{1}\right]$,

$$
\begin{aligned}
\|y(t)\| & \leq\left\|x_{0}\right\|+\frac{\Omega(r)}{\Gamma(\alpha)} \int_{0}^{t}(t-s)^{\alpha-1} \varphi(s) d s \\
& \leq\left\|x_{0}\right\|+\frac{\Omega(r)}{\Gamma(\alpha)}\|\varphi\|_{L^{p}\left(, \mathbb{R}^{+}\right)}\left(\int_{0}^{t}(t-s)^{\frac{(\alpha-1) p}{p-1}} d s\right)^{\frac{p-1}{p}} \\
& \leq\left\|x_{0}\right\|+\frac{\Omega(r)}{\Gamma(\alpha)}\|\varphi\|_{L^{p}\left(, \mathbb{R}^{+}\right)} b^{\alpha-\frac{1}{p}}\left(\frac{p-1}{\alpha p-1}\right)^{\frac{p-1}{p}} \\
& =\left\|x_{0}\right\|+\Omega(r) \eta\|\varphi\|_{L^{p}\left(, \mathbb{R}^{+}\right)} \leq r .
\end{aligned}
$$


If $t \in\left(t_{i} s_{i}\right],=1,2, \ldots, m$, then

$$
\|y(t)\| \leq\left\|g_{i}\left(t, x\left(t_{i}^{-}\right)\right)\right\| \leq h_{i}\left\|x\left(t_{i}^{-}\right)\right\| \leq h_{i} r \leq r .
$$

Similarly, for $t \in\left[s_{i} t_{i+1}\right], i=1,2, \ldots, m$, we get

$$
\begin{aligned}
& \|y(t)\| \\
& \quad \leq\left\|g_{i}\left(s_{i}, x\left(t_{i}^{-}\right)\right)\right\|+\frac{1}{\Gamma(\alpha)} \int_{0}^{s_{i}}\left(s_{i}-s\right)^{\alpha-1}\|f(s)\| d s+\frac{1}{\Gamma(\alpha)} \int_{0}^{t}(t-s)^{\alpha-1}\|f(s)\| d s \\
& \quad \leq h_{i} r+\frac{\Omega(r)}{\Gamma(\alpha)}\|\varphi\|_{L^{p}\left(J, \mathbb{R}^{+}\right)}\left[\left(\int_{0}^{s_{i}}\left(s_{i}-s\right)^{\frac{(\alpha-1) p}{p-1}} d s\right)^{\frac{p-1}{p}}+\left(\int_{0}^{t}(t-s)^{\frac{(\alpha-1) p}{p-1}} d s\right)^{\frac{p-1}{p}}\right] \\
& \quad \leq h_{i} r+2 \Omega(r) \eta\|\varphi\|_{L^{p}\left(J, \mathbb{R}^{+}\right)} \leq r .
\end{aligned}
$$

Therefore $R\left(B_{r}\right) \subseteq B_{r}$.

Next, for every $n \geq 1$, set $B_{n}=\overline{\operatorname{conv}} R\left(B_{n-1}\right)$. Note that $B_{n}$ is a non-empty, closed and convex subset of $\mathrm{PC}(J, E)$. Moreover, $B_{1}=\overline{\operatorname{conv}} R\left(B_{0}\right) \subseteq B_{0}$. Also $B_{2}=\overline{\operatorname{conv}} R\left(B_{1}\right) \subseteq \overline{\operatorname{conv}} R\left(B_{0}\right) \subseteq$ $B_{1}$. By induction, the sequence $\left(B_{n}\right), n \geq 1$ is a decreasing sequence of non-empty, closed and bounded subsets of $\mathrm{PC}(J, E)$. Set $B=\bigcap_{n=1}^{\infty} B_{n}$.

Now, by arguing as in Steps 1, 3 and 6 in the proof of Theorem 3.1 in [41], we see that the values of $R$ are closed, the set $Z_{\mid \bar{J}_{i}}$ is equicontinuous for every $i=0,1,2, \ldots, m$, and the graph of the multivalued function $R_{\mid B}: B \rightarrow 2^{B}$ is closed; here $Z=R\left(B_{0}\right)$ and

$$
Z_{\mid \overline{J_{i}}}=\left\{y^{*} \in C\left(\overline{J_{i}}, E\right): y^{*}(t)=y(t), t \in J_{i}, y^{*}\left(t_{i}\right)=y\left(t_{i}^{+}\right), y \in Z\right\}
$$

We now show that the subset $B=\bigcap_{n=1}^{\infty} B_{n}$ is non-empty and compact in $\mathrm{PC}(J, E)$. From the generalized Cantor intersection theorem [43], it is enough to show that

$$
\lim _{n \rightarrow \infty} \chi_{\mathrm{PC}}\left(B_{n}\right)=0
$$

where $\chi_{\mathrm{PC}}$ is the Hausdorff measure of noncompactness on $\mathrm{PC}(J, E)$ defined in Section 2.

Let $n \geq 1$ be a fixed natural number and $\varepsilon>0$. In view of [58], p.125, there exists a sequence $\left(y_{k}\right), k \geq 1$ in $R\left(B_{n-1}\right)$ such that

$$
\chi_{\mathrm{PC}}\left(B_{n}\right)=\chi_{\mathrm{PC}} R\left(B_{n-1}\right) \leq 2 \chi_{\mathrm{PC}}\left\{y_{k}: k \geq 1\right\}+\varepsilon
$$

From the definition of $\chi_{\mathrm{PC}}$, the above inequality becomes

$$
\chi_{\mathrm{PC}}\left(B_{n}\right) \leq 2 \max _{J=0,1, \ldots, m} \chi_{i}\left(S_{\overline{J_{i}}}\right)+\varepsilon
$$

where $S=\left\{y_{k}: k \geq 1\right\}$ and $\chi_{i}$ is the Hausdorff measure of noncompactness on $C\left(\overline{J_{i}}, E\right)$. Since $B_{n \mid \overline{T_{i}}}, J=0,1, \ldots, m$, is equicontinuous,

$$
\chi_{i}\left(S_{\mid \overline{J_{i}}}\right)=\sup _{t \in \overline{J_{i}}} \chi(S(t))
$$


where $\chi$ is the Hausdorff measure of noncompactness on $E$. Therefore, using the nonsingularity of $\chi,(15)$ becomes

$$
\begin{aligned}
\chi_{\mathrm{PC}}\left(B_{n}\right) & \leq 2 \max _{i=0,1, \ldots, m}\left[\sup _{t \in \bar{J}_{i}} \chi(S(t))\right]+\epsilon \\
& =2 \sup _{t \in J} \chi(S(t))+\varepsilon \\
& =2 \sup _{t \in J} \chi\left\{y_{k}(t): k \geq 1\right\}+\varepsilon .
\end{aligned}
$$

Now, since $y_{k} \in R\left(B_{n-1}\right), k \geq 1$ there is $x_{k} \in B_{n-1}$ such that $y_{k} \in R\left(x_{k}\right), k \geq 1$. Recalling the definition of $R$ for every $k \geq 1$ there is a $f_{k} \in S_{F\left(\cdot, x_{k}(\cdot)\right)}^{p}$ such that for every $t \in J$,

$$
\begin{aligned}
& \chi\left\{y_{k}(t): k \geq 1\right\} \\
& \quad \leq\left\{\begin{array}{l}
\frac{1}{\Gamma(\alpha)} \chi\left\{\int_{0}^{t}(t-s)^{\alpha-1} f_{k}(s) d s: k \geq 1\right\} \quad \text { if } t \in\left[0, t_{1}\right], \\
\chi\left\{g_{i}\left(t, x_{k}\left(t_{i}^{-}\right)\right): k \geq 1\right\} \quad \text { if } t \in\left(t_{i}, s_{i}\right], i=1,2, \ldots, m, \\
\chi\left\{g_{i}\left(s_{i}, x_{k}\left(t_{i}^{-}\right)\right): k \geq 1\right\} \\
\quad+\frac{1}{\Gamma(\alpha)} \chi\left\{\int_{0}^{s_{i}}\left(s_{i}-s\right)^{\alpha-1} f_{k}(s) d s: k \geq 1\right\} \\
\quad+\frac{1}{\Gamma(\alpha)} \chi\left\{\int_{0}^{t}(t-s)^{\alpha-1} f_{k}(s) d s: k \geq 1\right\} \quad \text { if } t \in\left[s_{i}, t_{i+1}\right], i=1,2, \ldots, m .
\end{array}\right.
\end{aligned}
$$

Note that, by the complete continuity of $g_{i}, i=1,2, \ldots, m$, we get

$$
\chi\left\{g_{i}\left(t, x_{k}\left(t_{i}^{-}\right)\right): k \geq 1\right\}=\chi\left\{g_{i}\left(s_{i}, x_{k}\left(t_{i}^{-}\right)\right): k \geq 1\right\}=0 .
$$

Next, we observe that from $\left(H_{3}\right)$, that for a.e. $t \in J$

$$
\begin{aligned}
\chi\left\{f_{k}(t): k \geq 1\right\} & \leq \chi\left\{F\left(s, x_{k}(t)\right): k \geq 1\right\} \\
& \leq \beta(t) \chi\left\{x_{k}(t): k \geq 1\right\} \\
& \leq \beta(t) \chi\left(B_{n-1}(t)\right) \\
& \leq \beta(t) \chi_{\mathrm{PC}}\left(B_{n-1}\right):=\gamma(t) .
\end{aligned}
$$

Furthermore, by $\left(H_{2}\right)$, for any $k \geq 1$ and for almost $t \in J,\left\|f_{k}(t)\right\| \leq \varphi(t) \Omega(r)$. Consequently, $f_{k} \in L^{p}(J, E), k \geq 1$. Note that $\gamma \in L^{p}\left(J, \mathbb{R}^{+}\right)$. Then, by virtue of [59], Lemma 4(iii), there exists a compact $K_{\epsilon} \subseteq E$, a measurable set $J_{\epsilon} \subset J$, with measure less than $\epsilon$, and a sequence of functions $\left\{z_{k}^{\epsilon}\right\} \subset L^{p}(J, E)$ such that, for all $s \in J,\left\{z_{k}^{\epsilon}(s): k \geq 1\right\} \subseteq K$ and

$$
\left\|f_{k}(s)-z_{k}^{\epsilon}(s)\right\|<2 \gamma(s)+\epsilon \quad \text { for every } k \geq 1 \text { and every } s \in J-J_{\epsilon} .
$$

Using (19) and Hölder's inequality, we get $k \geq 1$

$$
\begin{aligned}
& \left\|\int_{\left[0, t_{1}\right]-J_{\epsilon}}(t-s)^{\alpha-1}\left(f_{k}(s)-z_{k}^{\epsilon}(s)\right) d s\right\| \\
& \quad \leq \int_{\left[0, t_{1}\right]-J_{\epsilon}}(t-s)^{\alpha-1}\left\|f_{k}(s)-z_{k}^{\epsilon}(s)\right\| d s
\end{aligned}
$$




$$
\begin{aligned}
& \leq\left\|f_{k}-z_{k}^{\epsilon}\right\|_{L^{p}\left(\left[0, t_{1}\right]-J_{\epsilon}, E\right)}\left(\int_{\left[0, t_{1}\right]-J_{\epsilon}}(t-s)^{\frac{(\alpha-1) p}{p-1}} d s\right)^{\frac{p-1}{p}} \\
& \leq\left(2\|\gamma\|_{L^{p}\left(\left[0, t_{1}\right]-J_{\epsilon}, \mathbb{R}^{+}\right)}+\epsilon b^{p}\right) \eta \Gamma(\alpha) .
\end{aligned}
$$

From Hölder's inequality we get for any $k \geq 1$,

$$
\begin{aligned}
& \left\|\int_{J_{\epsilon}}(t-s)^{\alpha-1} f_{k}(s) d s\right\| \\
& \quad \leq \Omega(r) \int_{J_{\epsilon}}(t-s)^{\alpha-1} \varphi(s) d s \\
& \quad \leq \Omega(r)\|\varphi\|_{L^{p}\left(J_{\epsilon}, \mathbb{R}^{+}\right)}\left(\int_{J_{\epsilon}}(t-s)^{\frac{(\alpha-1) p}{p-1}} d s\right)^{\frac{p-1}{p}} \\
& \quad \leq \Omega(r)\|\varphi\|_{L^{p}\left(J_{\epsilon}, \mathbb{R}^{+}\right) \eta \Gamma(\alpha) .}
\end{aligned}
$$

From (21) and (22) we have, for $t \in\left[0, t_{1}\right]$,

$$
\begin{aligned}
\chi( & \left.\left\{\int_{0}^{t}(t-s)^{\alpha-1} f_{k}(s) d s: k \geq 1\right\}\right) \\
\leq & \chi\left(\left\{\int_{\left[0, t_{1}\right]-J_{\epsilon}}(t-s)^{\alpha-1} f_{k}(s) d s: k \geq 1\right\}\right) \\
& +\chi\left(\left\{\int_{J_{\epsilon}}(t-s)^{\alpha-1} f_{k}(s) d s: k \geq 1\right\}\right) \\
\leq & \chi\left(\left\{\int_{\left[0, t_{1}\right]-J_{\epsilon}}(t-s)^{\alpha-1}\left(f_{k}(s)-z_{k}^{\epsilon}(s)\right) d s: k \geq 1\right\}\right) \\
& +\chi\left(\left\{\int_{\left[0, t_{1}\right]-J_{\epsilon}}(t-s)^{\alpha-1} z_{k}^{\epsilon}(s) d s: k \geq 1\right\}\right) \\
& +\chi\left(\left\{\int_{J_{\epsilon}}(t-s)^{\alpha-1} f_{k}(s) d s: k \geq 1\right\}\right) \\
\leq & \left(2\|\beta\|_{L^{p}\left(\left[0, t_{1}\right]-J_{\epsilon}, \mathbb{R}^{+}\right)} \chi_{\mathrm{PC}}\left(B_{n-1}\right)+\epsilon b^{p}\right) \eta \Gamma(\alpha)+\Omega(r)\|\varphi\|_{L^{p}\left(J_{\epsilon}, \mathbb{R}^{+}\right) \eta \Gamma(\alpha) .}
\end{aligned}
$$

Taking into account that $\varepsilon$ is arbitrary, the inequality (23) gives us for all $t \in\left[0, t_{1}\right]$,

$$
\chi\left(\left\{\int_{0}^{t}(t-s)^{\alpha-1} f_{k}(s) d s: k \geq 1\right\}\right) \leq 2\|\beta\|_{L^{p}\left(\left[0, t_{1}\right], \mathbb{R}^{+}\right)} \chi_{\mathrm{PC}}\left(B_{n-1}\right) \eta \Gamma(\alpha) .
$$

Similarly, we can show that if $t \in\left[s_{i}, t_{i+1}\right], i=1,2, \ldots, m$, then

$$
\chi\left\{\int_{0}^{s_{i}}\left(s_{i}-s\right)^{\alpha-1} f_{k}(s) d s: k \geq 1\right\} \leq 2\|\beta\|_{\left.L^{p}\left(s_{i}, t_{i+1}\right], \mathbb{R}^{+}\right)} \chi_{\mathrm{PC}}\left(B_{n-1}\right) \eta \Gamma(\alpha)
$$

and

$$
\chi\left\{\int_{0}^{t}(t-s)^{\alpha-1} f_{k}(s) d s: k \geq 1\right\} \leq 2\|\beta\|_{L^{p}\left(\left[s_{i}, t_{i+1}\right], \mathbb{R}^{+}\right)} \chi_{\mathrm{PC}}\left(B_{n-1}\right) \eta \Gamma(\alpha) .
$$


From (17), (18), (24), (25) and (26) for every $t \in J$,

$$
\chi\left\{y_{k}(t): k \geq 1\right\} \leq 8\|\beta\|_{L^{\frac{1}{q}\left(J, \mathbb{R}^{+}\right)}} \chi_{\mathrm{PC}}\left(B_{n-1}\right) \eta .
$$

Now (27), (16) and the fact that $\varepsilon$ is arbitrary, yields

$$
\chi_{\mathrm{PC}}\left(B_{n}\right) \leq 8\|\beta\|_{L^{\frac{1}{\bar{q}}\left(J, \mathbb{R}^{+}\right)}} \chi_{\mathrm{PC}}\left(B_{n-1}\right) \eta,
$$

so

$$
0 \leq \chi_{\mathrm{PC}}\left(B_{n}\right) \leq\left(8 \eta\|\beta\|_{L^{p}\left(J, \mathbb{R}^{+}\right)}\right)^{n-1} \chi_{\mathrm{PC}}\left(B_{1}\right), \quad \forall n \geq 1 .
$$

Since this inequality is true for every $n \in \mathbb{N}$, from (8) and by passing to the limit as $n \rightarrow+\infty$, we obtain (14).

From the generalized Cantor intersection property the set $B=\bigcap_{n=1}^{\infty} B_{n}$ is a non-empty and compact subset of $\mathrm{PC}(J, E)$. Moreover, since every $B_{n}$ is bounded, closed and convex, $B$ is also bounded closed and convex. We now claim that $R(B) \subseteq B$. Indeed, $R(B) \subseteq R\left(B_{n}\right) \subseteq$ $\overline{\operatorname{conv}} R\left(B_{n}\right)=B_{n+1}$, for every $n \geq 1$. Therefore, $R(B) \subset \bigcap_{n=2}^{\infty} B_{n}$. Also $B_{n} \subset B_{1}$ for every $n \geq 1$, so $R(B) \subset \bigcap_{n=2}^{\infty} B_{n}=\bigcap_{n=1}^{\infty} B_{n}=B$.

Therefore, the multivalued $R_{\mid B}: B \rightarrow 2^{B}$ is a closed compact map with non-empty convex compact values, and hence u.s.c. From Lemma 2.10, there is a $x \in B$ such that $x \in R(x)$. Thus $x$ is a PC-mild solution for (3).

In the following theorem we prove that the set of PC-mild solutions of (3) is compact.

Theorem 3.2 If the function $\Omega$ in (H2) is of the form $\Omega(r)=r+1$, then under the assumptions of Theorem 3.1 the set of solutions of (3) is a non-empty compact subset in $\mathrm{PC}(J, E)$ provided that

$$
\bar{h}+2 \eta\|\varphi\|_{L^{p}\left(, \mathbb{R}^{+}\right)}<1 .
$$

Proof From Theorem 3.1 the set of solutions of (3) is non-empty. Indeed, let $R: \mathrm{PC}(J, E) \rightarrow$ $2^{\mathrm{PC}(J, E)}$ be defined as in Theorem 3.1 and we take $r$ in (9) as

$$
r=\frac{\left\|x_{0}\right\|+2 \eta\|\varphi\|_{L^{p}\left(J, \mathbb{R}^{+}\right)}}{1-\left(\bar{h}+2 \eta\|\varphi\|_{L^{p}\left(J, \mathbb{R}^{+}\right)}\right)} .
$$

Note $r$ is well defined because of (28). From Theorem 3.1 we know that the problem (3) has a PC-mild solution in $B$. Now, by arguing as in the proof of Theorem 3.1, there is a non-empty convex compact subset $B$ such that $R_{\mid B}: B \rightarrow 2^{B}$ is a closed compact map with non-empty convex compact values. Then $R_{\mid B}$ is $\gamma_{\mathrm{PC}}$-condensing on every bounded subset of $B$. From Lemma 2.11, in order to show that the set of solutions of (3) is compact, it suffices to prove that the set of fixed points of $R$ is bounded. Let $x$ be a fixed point of $R$. 
Then there is an integrable selection $f$ for $F(\cdot, x(\cdot))$ such that

$$
x(t)=\left\{\begin{array}{l}
x_{0}+\frac{1}{\Gamma(\alpha)} \int_{0}^{t}(t-s)^{\alpha-1} f(s) d s, \quad t \in\left[0, t_{1}\right], \\
g_{i}\left(t, x\left(t_{i}^{-}\right)\right), \quad t \in\left(t_{i}, s_{i}\right], i=1,2, \ldots, m, \\
g_{i}\left(s_{i}, x\left(t_{i}^{-}\right)\right)+\frac{1}{\Gamma(\alpha)} \int_{s_{i}}^{t}(t-s)^{\alpha-1} f(s) d s \\
\quad+\frac{1}{\Gamma(\alpha)} \int_{0}^{t}(t-s)^{\alpha-1} f(s) d s, \quad t \in\left[s_{i}, t_{i+1}\right], i=1,2, \ldots, m .
\end{array}\right.
$$

We argue as in Theorem 3.1 and we get

$$
\|x\|_{\mathrm{PC}(J, E)} \leq\left\|x_{0}\right\|+\bar{h}\|x\|_{\mathrm{PC}(J, E)}+2\left(\|x\|_{\mathrm{PC}(, E)}+1\right) \eta\|\varphi\|_{L^{p}\left(J, \mathbb{R}^{+}\right)} .
$$

From (28), we obtain

$$
\|x\|_{\mathrm{PC}(, E)} \leq \frac{\left\|x_{0}\right\|+2 \eta\|\varphi\|_{L^{p}\left(J, \mathbb{R}^{+}\right)}}{1-\left(\bar{h}+2 \eta\|\varphi\|_{L^{p}\left(J, \mathbb{R}^{+}\right)}\right)}=r .
$$

Finally, from Lemma 2.11, the proof is complete.

In the following theorem we will show that if we use the Bielecki PCB-norm, then we can establish an existence result for (3) without assuming a condition similar to (9).

Theorem 3.3 Let $F: J \times E \rightarrow P_{c k}(E)$ and $g_{i}:\left[t_{i}, s_{i}\right] \times E \rightarrow E, i=1,2, \ldots, m$. Assume the following assumptions hold:

$\left(H_{5}\right)$ For every $x \in E, t \longrightarrow F(t, x)$ is measurable.

$\left(H_{6}\right)$ There is a $\varsigma \in L^{p}\left(J, \mathbb{R}^{+}\right), p>\frac{1}{\alpha}$ such that

(i) For every $x, y \in E$,

$$
h(F(t, x), F(t, y)) \leq \varsigma(t)\|x-y\|, \quad \text { for a.e. } t \in J,
$$

where $h: P_{c k}(E) \times P_{c k}(E) \rightarrow \mathbb{R}^{+}$is the Hausdorff distance.

(ii) For every $x \in E$,

$$
\sup \{\|x\|: x \in F(t, 0)\} \leq \varsigma(t), \quad \text { for a.e. } t \in J
$$

$\left(H_{7}\right)$ For all $i=1,2, \ldots, m$, there is a positive constant $\xi_{i}$ such that, for every $x, y \in E$ and every $t \in\left[t_{i}, s_{i}\right]$, we have

$$
\left\|g_{i}(t, x)-g_{i}(t, y)\right\| \leq \xi_{i}\|x-y\| .
$$

Then (3) has a PC-mild solution.

Proof From $\left(H_{5}\right)$ and $\left(H_{6}\right)$, for any $x \in \mathrm{PC}(J, E)$, the set $S_{F(\cdot, x(\cdot))}^{p}$ is non-empty. Consider the multifunction map $R: \mathrm{PC}(J, E) \rightarrow 2^{\mathrm{PC}(J, E)}$ as follows: for $x \in \mathrm{PC}(J, E), R(x)$ is the set of all functions $y \in R(x)$ such that (10) holds. It is easy to see that any fixed point for $R$ is a PC-mild solution for (3). We now show that $R$ satisfies the assumptions of Lemma 2.12. 
Note from $\left(H_{6}\right)$, for every $n \geq 1$, and for $t \in J$,

$$
\begin{aligned}
\|F(t, x)\| & =h(F(t, x(t)),\{0\}) \\
& \leq h(F(t, x(t)), F(t, 0))+h(F(t, 0),\{0\}) \\
& \leq \varsigma(t)\|x(t)\|+\varsigma(t) \leq \varsigma(t)\left(1+\|x\|_{\mathrm{PC}(J, E)}\right) .
\end{aligned}
$$

Arguing as in Step 1 in the proof of Theorem 3.3 in [41], we see that the values of $R$ are closed.

We now show that $R$ is contraction. Let $x_{1}, x_{2} \in \mathrm{PC}(J, E)$ and $y_{1} \in R\left(x_{1}\right)$. Then there is a $f \in S_{F\left(\cdot, x_{1}(\cdot)\right)}^{p}$ such that

$$
y_{1}(t)=\left\{\begin{aligned}
x_{0}+\frac{1}{\Gamma(\alpha)} \int_{0}^{t}(t-s)^{\alpha-1} f(s) d s, \quad t \in\left[0, t_{1}\right], \\
g_{i}\left(t, g_{i-1}\left(s_{i-1}, x_{1}\left(t_{i-1}^{-}\right)\right)-\frac{1}{\Gamma(\alpha)} \int_{0}^{s_{i-1}}\left(s_{i-1}-s\right)^{\alpha-1} f(s) d s\right. \\
\left.\quad+\frac{1}{\Gamma(\alpha)} \int_{0}^{t_{i}}\left(t_{i}-s\right)^{\alpha-1} f(s) d s\right), \quad t \in\left(t_{i}, s_{i}\right],=1,2, \ldots, m, \\
g_{i}\left(s_{i}, x_{1}\left(t_{i}^{-}\right)\right)-\frac{1}{\Gamma(\alpha)} \int_{0}^{s_{i}}\left(s_{i}-s\right)^{\alpha-1} f(s) d s \\
\quad+\frac{1}{\Gamma(\alpha)} \int_{0}^{t}(t-s)^{\alpha-1} f(s) d s, \quad t \in\left[s_{i}, t_{i+1}\right], i=1,2, \ldots, m .
\end{aligned}\right.
$$

Next, since $F\left(t, x_{2}(t)\right)$ is compact for any $t \in J$, the set $U(t)=\left\{x \in F\left(t, x_{2}(t)\right): d(f(t), x)=\right.$ $d(f(t), G(t))\}$ is non-empty. According to Lemma 2.9, there is a measurable function $h$ : $J \rightarrow E$ such that $h(t) \in F\left(t, x_{2}(t)\right)$, a.e. and

$$
\|f(t)-h(t)\|=d\left(f(t), F\left(t, x_{2}(t)\right)\right), \quad \text { for a.e. } t \in J .
$$

Observe that from $\left(H_{6}\right)(\mathrm{i})$, we have

$$
h\left(F\left(t, x_{2}(t)\right), F\left(t, x_{1}(t)\right)\right) \leq \varsigma(t)\left\|x_{1}(t)-x_{2}(t)\right\|, \quad \text { for a.e. } t \in J .
$$

Then $h \in S_{F\left(\cdot, x_{2}(\cdot)\right)}^{p}$ with

$$
\|h(t)-f(t)\| \leq \varsigma(t)\left(\left\|x_{2}(t)-x_{1}(t)\right\|\right), \quad \text { for a.e. } t \in J \text {. }
$$

Let

$$
y_{2}(t)=\left\{\begin{array}{l}
x_{0}+\frac{1}{\Gamma(\alpha)} \int_{0}^{t}(t-s)^{\alpha-1} h(s) d s, \quad t \in\left[0, t_{1}\right], \\
g_{i}\left(t, g_{i-1}\left(s_{i-1}, x_{2}\left(t_{i-1}^{-}\right)\right)-\frac{1}{\Gamma(\alpha)} \int_{0}^{t_{i-1}}\left(t_{i-1}-s\right)^{\alpha-1} h(s) d s\right. \\
\left.\quad+\frac{1}{\Gamma(\alpha)} \int_{0}^{t_{i}}\left(t_{i}-s\right)^{\alpha-1} h(s) d s\right), \quad t \in\left(t_{i}, s_{i}\right],=1,2, \ldots, m, \\
g_{i}\left(s_{i}, x_{2}\left(t_{i}^{-}\right)\right)-\frac{1}{\Gamma(\alpha)} \int_{0}^{s_{i}}\left(s_{i}-s\right)^{\alpha-1} h(s) d s \\
\quad+\frac{1}{\Gamma(\alpha)} \int_{0}^{t}(t-s)^{\alpha-1} h(s) d s, \quad t \in\left[s_{i}, t_{i+1}\right], i=1,2, \ldots, m .
\end{array}\right.
$$

Now $y_{2} \in R\left(x_{2}\right)$ and if $t \in\left[0, t_{1}\right]$ we get from (30), (31) and Hölder's inequality

$$
\begin{aligned}
& e^{-L t}\left\|y_{2}(t)-y_{1}(t)\right\| \\
& \quad \leq \frac{e^{-L t}}{\Gamma(\alpha)} \int_{0}^{t}(t-s)^{\alpha-1}\|h(s)-f(s)\| d s
\end{aligned}
$$




$$
\begin{aligned}
& \leq \frac{e^{-L t}}{\Gamma(\alpha)} \int_{0}^{t}(t-s)^{\alpha-1} \zeta(s) e^{L s}\left(e^{-L s}\left\|x_{1}(s)-x_{2}(s)\right\|\right) d s \\
& \leq \frac{e^{-L t}}{\Gamma(\alpha)}\left\|x_{1}-x_{2}\right\|_{\mathrm{PCB}(J, E)} \int_{0}^{t}(t-s)^{\alpha-1} e^{L s} \varsigma(s) d s \\
& \leq \frac{1}{\Gamma(\alpha)}\left\|x_{1}-x_{2}\right\|_{\mathrm{PCB}(, E)} \int_{0}^{t}(t-s)^{\alpha-1} e^{-L(t-s)} \varsigma(s) d s \\
& \leq \frac{t^{\alpha-\frac{1}{p}}}{\Gamma(\alpha)}\left(\frac{p-1}{\alpha p-1}\right)^{\frac{p-1}{p}}\left\|x_{1}-x_{2}\right\|_{\mathrm{PCB}(J, E)}\left(\int_{0}^{t}\left(e^{-L(t-s)} \varsigma(s)\right)^{p} d s\right)^{\frac{1}{p}} .
\end{aligned}
$$

Also, if $t \in\left[s_{i} t_{i+1}\right], i=1,2, \ldots, m$, we get

$$
\begin{aligned}
\| y_{2}(t) & -y_{1}(t) \| \\
\leq & \left\|g_{i}\left(t, x_{1}\left(t_{i}^{-}\right)\right)-g_{i}\left(t, x_{2}\left(t_{i}^{-}\right)\right)\right\| \\
& +\frac{1}{\Gamma(\alpha)} \int_{0}^{s_{i}}\left(s_{i}-s\right)^{\alpha-1}\|h(s)-f(s)\| d s \\
& +\frac{1}{\Gamma(\alpha)} \int_{0}^{t}(t-s)^{\alpha-1}\|h(s)-f(s)\| d s \\
\leq & \xi_{i}\left\|x_{1}\left(t_{i}^{-}\right)-x_{2}\left(t_{i}^{-}\right)\right\| \\
& +\frac{1}{\Gamma(\alpha)}\left\|x_{1}-x_{2}\right\|_{\operatorname{PCB}(J, E)} \int_{0}^{s_{i}}\left(s_{i}-s\right)^{\alpha-1} e^{L s} \varsigma(s) d s \\
& +\frac{1}{\Gamma(\alpha)}\left\|x_{1}-x_{2}\right\|_{\operatorname{PCB}(J, E)} \int_{0}^{t}(t-s)^{\alpha-1} e^{L s} s(s) d s .
\end{aligned}
$$

Then

$$
\begin{aligned}
e^{-L t} & \left\|y_{2}(t)-y_{1}(t)\right\| \\
\leq & {\left[e^{-L t} e^{L t_{i}} \xi_{i}+\frac{s_{i}^{\alpha-\frac{1}{p}}}{\Gamma(\alpha)}\left(\frac{p-1}{\alpha p-1}\right)^{\frac{p-1}{p}}\left(\int_{0}^{s_{i}}\left(e^{-L(t-s)} \zeta(s)\right)^{p} d s\right)^{\frac{1}{p}}\right.} \\
& \left.+\frac{t^{\alpha-\frac{1}{p}}}{\Gamma(\alpha)}\left(\frac{p-1}{\alpha p-1}\right)^{\frac{p-1}{p}}\left(\int_{0}^{t}\left(e^{-L(t-s)} S(s)\right)^{p} d s\right)^{\frac{1}{p}}\right]\left\|x_{1}-x_{2}\right\|_{\mathrm{PCB}(J, E)} \\
\leq & \left\|x_{1}-x_{2}\right\|_{\mathrm{PCB}(J, E)}\left[e^{L\left(t_{i}-t\right)} \xi_{i}\right. \\
& \left.+2 \frac{t^{\alpha-\frac{1}{p}}}{\Gamma(\alpha)}\left(\frac{p-1}{\alpha p-1}\right)^{\frac{p-1}{p}}\left(\int_{0}^{t}\left(e^{-L(t-s)} \varsigma(s)\right)^{p} d s\right)^{\frac{1}{p}}\right] \\
\leq & \left\|x_{1}-x_{2}\right\|_{\mathrm{PCB}(J, E)}\left[e^{L\left(t_{i}-s_{i}\right)} \xi_{i}+\frac{2 t^{\alpha-\frac{1}{p}}}{\Gamma(\alpha)}\left(\frac{p-1}{\alpha p-1}\right)^{\frac{p-1}{p}}\left(\int_{0}^{t}\left(e^{-L(t-s)} \varsigma(s)\right)^{p} d s\right)^{\frac{1}{p}}\right] .
\end{aligned}
$$

Similarly, if $t \in\left(t_{i} s_{i}\right], i=1,2, \ldots, m$, we get from (28), (29), (30) and $\left(H_{7}\right)$,

$$
\begin{aligned}
\left\|y_{2}(t)-y_{1}(t)\right\| \leq & \xi_{i}\left(\xi_{i-1}\left\|x_{1}\left(t_{i-1}^{-}\right)-x_{2}\left(t_{i-1}^{-}\right)\right\|\right. \\
& +\frac{1}{\Gamma(\alpha)} \int_{0}^{t_{i-1}}\left(t_{i-1}-s\right)^{\alpha-1}\|f(s)-h(s)\| d s
\end{aligned}
$$




$$
\begin{aligned}
& \left.+\frac{1}{\Gamma(\alpha)} \int_{0}^{t}(t-s)^{\alpha-1}\|f(s)-h(s)\| d s\right) \\
\leq & \xi_{i}\left(\xi_{i-1}\left\|x_{1}\left(t_{i}^{-}\right)-x_{2}\left(t_{i}^{-}\right)\right\|\right. \\
& +\frac{1}{\Gamma(\alpha)} \int_{0}^{t_{i-1}}\left(t_{i-1}-s\right)^{\alpha-1} \varsigma(s)\left\|x_{2}(s)-x_{1}(s)\right\| d s \\
& \left.+\frac{1}{\Gamma(\alpha)} \int_{0}^{t}(t-s)^{\alpha-1} \varsigma(s)\left\|x_{2}(s)-x_{1}(s)\right\| d s\right) .
\end{aligned}
$$

Then, for $t \in\left(t_{i}, s_{i}\right], i=1,2, \ldots, m$,

$$
\begin{aligned}
e^{-L t}\left\|y_{2}(t)-y_{1}(t)\right\| \\
\leq e^{-L t} \xi_{i} \xi_{i-1}\left\|x_{1}\left(t_{i-1}^{-}\right)-x_{2}\left(t_{i-1}^{-}\right)\right\| \\
\quad+\frac{\xi_{i}}{\Gamma(\alpha)}\left\|x_{2}-x_{1}\right\|_{\mathrm{PCB}(J, E)} \int_{0}^{t_{i-1}}\left(t_{i-1}-s\right)^{\alpha-1} e^{-L(t-s)} \zeta(s) d s \\
\quad+\frac{\xi_{i}}{\Gamma(\alpha)}\left\|x_{2}-x_{1}\right\|_{\mathrm{PCB}(J, E)} \int_{0}^{t_{i}}\left(t_{i}-s\right)^{\alpha-1} e^{-L(t-s)} \varsigma(s) d s \\
\leq\left\|x_{2}-x_{1}\right\|_{\mathrm{PCB}(J) E)} \xi_{i}\left[\xi_{i-1} e^{-L t} e^{L t_{i-1}}\right. \\
\left.\quad+\left(\frac{t_{i-1}^{\alpha-\frac{1}{p}}}{\Gamma(\alpha)}\left(\frac{p-1}{\alpha p-1}\right)^{\frac{p-1}{p}}+\frac{t_{i}^{\alpha-\frac{1}{p}}}{\Gamma(\alpha)}\left(\frac{p-1}{\alpha p-1}\right)^{\frac{p-1}{p}}\right)\left(\int_{0}^{t}\left(e^{-L(t-s)} \varsigma(s)\right)^{p} d s\right)^{\frac{1}{p}}\right] .
\end{aligned}
$$

Therefore,

$$
\begin{aligned}
e^{-L t}\left\|y_{2}(t)-y_{1}(t)\right\| \leq & \left\|x_{2}-x_{1}\right\|_{\operatorname{PCB}(, E)} \xi_{i}\left[\xi_{i-1} e^{-L\left(t_{i}-t_{i-1}\right)}\right. \\
& \left.+\frac{2 t^{\alpha-\frac{1}{p}}}{\Gamma(\alpha)}\left(\frac{p-1}{\alpha p-1}\right)^{\frac{p-1}{p}}\left(\int_{0}^{t}\left(e^{-L(t-s)} \varsigma(s)\right)^{p} d s\right)^{\frac{1}{p}}\right] .
\end{aligned}
$$

From (32), (33), (34), we get

$$
\left\|R\left(x_{2}\right)-R\left(x_{1}\right)\right\|_{\mathrm{PCB}(J, E)}<K\left\|x_{1}-x_{2}\right\|_{\mathrm{PCB}(, E)},
$$

where

$$
\begin{aligned}
K= & \max \left\{\operatorname { m a x } _ { 1 \leq i \leq m } \xi _ { i } \left[\xi_{i-1} e^{-L\left(t_{i}-t_{i-1}\right)}\right.\right. \\
& \left.+\frac{2}{\Gamma(\alpha)}\left(\frac{p-1}{\alpha p-1}\right)^{\frac{p-1}{p}} \max _{t \in J} t^{\alpha-\frac{1}{p}}\left(\int_{0}^{t}\left(e^{-L(t-s)} \varsigma(s)\right)^{p} d s\right)^{\frac{1}{p}}\right], \\
& \left.\max _{1 \leq i \leq m} e^{-L\left(s_{i}-t_{i}\right)} \xi_{i}+\frac{2}{\Gamma(\alpha)}\left(\frac{p-1}{\alpha p-1}\right)^{\frac{p-1}{p}} \max _{t \in J} t^{\alpha-\frac{1}{p}}\left(\int_{0}^{t}\left(e^{-L(t-s)} \varsigma(s)\right)^{p} d s\right)^{\frac{1}{p}}\right\} .
\end{aligned}
$$

We can choose a sufficiently large $L$ such that $K<1$ and so $R$ is contraction. Thus, from Lemma $2.12, R$ has a fixed point which is a mild solution for (3). 
Remark 3.4 If we take $\varsigma(\cdot)=M_{F}$, where $M_{F}$ is a positive real number, in Theorem 3.3, then we can choose

$$
\begin{aligned}
K= & \max \left\{\max _{1 \leq i \leq m} \xi_{i} \xi_{i-1} e^{-L\left(t_{i}-t_{i-1}\right)}+\frac{2 \xi_{i}}{\Gamma(\alpha)}\left(\frac{p-1}{\alpha p-1}\right)^{\frac{p-1}{p}} \frac{M_{F}}{(L p)^{\frac{1}{p}}} \max _{t \in J} t^{\alpha-\frac{1}{p}},\right. \\
& \left.\max _{1 \leq i \leq m} e^{-L\left(s_{i}-t_{i}\right)} \xi_{i}+\frac{2}{\Gamma(\alpha)}\left(\frac{p-1}{\alpha p-1}\right)^{\frac{p-1}{p}} \frac{M_{F}}{(L p)^{\frac{1}{p}}} \max _{t \in J} t^{\alpha-\frac{1}{p}}\right\},
\end{aligned}
$$

where we use the fact that

$$
\int_{0}^{t} e^{-L(t-s) p} d s=\frac{1-e^{-L t p}}{L p} \leq \frac{1}{L p}, \quad t \in J .
$$

\section{Concepts and results for generalized Ulam-Hyers stability}

In this section we introduce the concept of generalized Ulam-Hyers stability for (3). First we give some basic definitions and results on multivalued weakly Picard operators [60, 61 .

Definition 4.1 Let $(X, d)$ be a metric space. A multivalued operator $R: X \rightarrow P_{c l}(X)$ is said to be a multivalued weakly Picard operator (MWPO), if for each $u \in X$, and each $v \in R(u)$, there exists a sequence $\left(u_{n}\right)$ such that

(i) $u_{0}=u, u_{1}=v$;

(ii) $u_{n+1} \in R\left(u_{n}\right), n \in \mathbb{N}$;

(iii) the sequence $\left(u_{n}\right)$ is convergent and its limit is a fixed point of $R$.

Note that each $M W P O$ has at least a fixed point.

Remark 4.2 A sequence $\left(u_{n}\right)$ satisfying conditions (i) and (ii) in Definition 4.1 is called a sequence of successive approximations of $R$ starting from $(u, v) \in \operatorname{Graph}(R)$.

Definition 4.3 Let $(X, d)$ be a metric space and $\Psi:[0, \infty) \rightarrow[0, \infty)$ be an increasing function which is continuous at 0 and $\Psi(0)=0$.

A multivalued operator $R: X \rightarrow P_{c l}(X)$ is said to be a $\Psi$-weakly multivalued Picard operator ( $\Psi$-MWPO) if it is a weakly multivalued Picard operator and there is a function $R^{\infty}: \operatorname{Graph}(R) \rightarrow \operatorname{Fix}(R)$ such that:

(i) $z=R^{\infty}(u, v)$ if and only if there is sequence of successive approximations of $R$ starting from $(u, v)$ that converges to $z$.

(ii) for all $(u, v) \in \operatorname{Graph}(R)$, we have $d\left(u, R^{\infty}(u, v)\right) \leq \Psi(d(u . v))$.

If there exists $c>0$ such that $\Psi(t)=c t$, for each $t \in[0, \infty)$, then $R$ is called a $c$-weakly multivalued Picard operator (c-MWPO).

Definition 4.4 Let $(X, d)$ be a metric space and $\gamma \in(0,1)$. A multivalued operator $R: X \rightarrow$ $P_{c l}(X)$ is said to be a $\gamma$-contraction if

$$
h(R(x), R(y)) \leq \gamma d(x, y), \quad \forall x, y \in X .
$$

Remark 4.5 Let $(X, d)$ be a complete metric space and $\gamma \in(0,1)$. If $R: X \rightarrow P_{c l}(X)$ is a $\gamma$-contraction, then it is a c-MWPO, where $c=(1-\gamma)^{-1}$. 
Let us recall the notation of a comparison function $[50,62]$.

Definition 4.6 A function $\varphi:[0, \infty) \rightarrow[0, \infty)$ is said to be comparison function if it is increasing and for any $t \in[0, \infty), \varphi^{n}(t) \rightarrow 0$ as $n \rightarrow \infty$, where $\varphi^{n}(t)=\varphi^{n-1}(\varphi(t))$.

As a consequence, we also have $\varphi(t)<t$, for each $t>0, \varphi(0)=0$ and $\varphi$ is continuous at 0 .

Definition 4.7 A function $\varphi:[0, \infty) \rightarrow[0, \infty)$ is said to be strictly comparison function if it is strictly increasing and $\sum_{n=1}^{\infty} \varphi^{n}(t)<\infty$, for each $t>0$.

Example 4.8 The mappings $\varphi_{1}, \varphi_{2}:[0, \infty) \rightarrow[0, \infty)$ given by $\varphi_{1}(t)=c t, c \in[0,1), \varphi_{2}(t)=$ $\frac{t}{t+1}, t \in[0, \infty)$, are strictly comparison functions.

Definition 4.9 Let $(X, d)$ be a metric space and $\varphi:[0, \infty) \rightarrow[0, \infty)$ be strictly comparison. A multivalued operator $R: X \rightarrow P_{c l}(X)$ is said to be a $\varphi$-contraction if

$$
h(R(x), R(y)) \leq \varphi(d(x, y)), \quad \forall x, y \in X
$$

The following result is a generalization of the Covitz-Nadler fixed point theorem and is known in the literature as Wegrzyk's fixed point theorem [62].

Lemma 4.10 Let $(X, d)$ be a complete metric space and $\varphi:[0, \infty) \rightarrow[0, \infty)$ be strictly comparison. If the multivalued operator $R: X \rightarrow P_{c l}(X)$ is a $\varphi$-contraction, then there is $x \in$ $X$ with $x \in R(x)$ and for any $u_{0} \in X$, there is a sequence $\left(u_{n}\right)$ in $X$ such that $u_{n} \in R\left(u_{n-1}\right), n \in$ $\mathbb{N}$, and the sequence $\left(u_{n}\right)$ is convergent and its limit is a fixed point of $R$.

Also, the following result is known as Wegrzyk's theorem [62].

Lemma 4.11 Let $(X, d)$ be a complete metric space and $\varphi:[0, \infty) \rightarrow[0, \infty)$ be strictly comparison. If the multivalued operator $R: X \rightarrow P_{c l}(X)$ is a $\varphi$-contraction, then it is a MWPO, and hence it has a fixed point.

The following lemma was proved in [63].

Lemma 4.12 Let $(X, d)$ be a complete metric space and $\varphi:[0, \infty) \rightarrow[0, \infty)$ be strictly comparison. If the multivalued operator $R: X \rightarrow P_{c l}(X)$ is a $\varphi$-contraction, then

(i) $R$ is a MWPO, and hence it has a fixed point.

(ii) If additionally, there is a $c>1$ such that $\varphi(c t) \leq c \varphi(t)$, for every $t \in[0, \infty)$ and $t=0$ is a point of uniform convergence for the series $\sum_{n=1}^{\infty} \varphi^{n}(t)$, then $R$ is a $\Psi$-MWPO with $\Psi(t)=t+\sum_{n=1}^{\infty} \varphi^{n}(t)$.

Following [33], we first introduce the definition of Ulam-Hyers stability for (3), and then we extend it to the generalized Ulam-Hyers stability case.

Set $Z=\operatorname{PC}(J, E) \bigcap_{i=0}^{i=m} C^{1}\left(\left(s_{i}, t_{i+1}\right), E\right)$. 
Definition 4.13 Equation (3) is said to be Ulam-Hyers stable if there exists a positive real number $C_{F m g}$ such that, for each $\epsilon>0$ and each solution $y \in Z$ of the inequalities

$$
\left\{\begin{array}{l}
d\left({ }^{c} D_{0, t}^{\alpha} y(t), F(t, y(t))\right) \leq \epsilon \quad \text { a.e. } t \in\left(s_{i}, t_{i+1}\right], i=0,1, \ldots, m, \\
\left\|y(t)-g_{i}\left(t, y\left(t_{i}^{-}\right)\right)\right\| \leq \epsilon, \quad t \in\left(t_{i}, s_{i}\right], i=1, \ldots, m, \\
\left\|y\left(t_{i}^{+}\right)-g_{i}\left(t_{i}, y\left(t_{i}^{-}\right)\right)\right\| \leq \epsilon, \quad i=1, \ldots, m,
\end{array}\right.
$$

there is a mild solution $x \in \mathrm{PC}(J, E)$ for (3) such that

$$
\|x(t)-y(t)\| \leq \epsilon C_{F m g}, \quad \forall t \in J .
$$

Definition 4.14 Equation (3) is said to be generalized Ulam-Hyers stable if there exists an increasing function $\theta:[0, \infty) \rightarrow[0, \infty)$, which is continuous at $t=0$ and $\theta(0)=0$ such that, for each $\epsilon>0$ and each solution $y \in Z$ of the inequality (35), there is a mild solution $x \in \mathrm{PC}(J, E)$ for (3) such that

$$
\|x(t)-y(t)\| \leq \theta(\epsilon), \quad \forall t \in J .
$$

In the following we show that (3) has a mild solution which is generalized Ulam-Hyers stable.

Theorem 4.15 Let $F: J \times E \longrightarrow P_{c k}(E)$ be a multifunction and $g_{i}:\left[t_{i}, s_{i}\right] \times E \rightarrow E(i=$ $1,2, \ldots, m)$. We suppose $\left(H_{5}\right)$ and the following assumptions:

$\left(H_{8}\right)$ There is a function $\varsigma \in L^{p}\left(J, \mathbb{R}^{+}\right), p>\frac{1}{\alpha}$ and a strict comparison function $\varphi:[0, \infty) \rightarrow$ $[0, \infty)$ such that

(i) For every $x, y \in E$,

$$
h(F(t, x), F(t, y)) \leq \varsigma(t) \varphi(\|x-y\|), \quad \text { for a.e. } t \in J .
$$

(ii) For every $x \in E$

$$
\sup \{\|x\|: x \in F(t, 0)\} \leq \varsigma(t), \quad \text { for a.e. } t \in J
$$

$\left(H_{9}\right)$ For all $i=1,2, \ldots, m$, there is a positive constant $\xi_{i}$ such that for every $x, y \in E$ and every $t \in\left[t_{i}, s_{i}\right]$ we have

$$
\left\|g_{i}(t, x)-g_{i}(t, y)\right\| \leq \xi_{i} \varphi(\|x-y\|) .
$$

Then (3) has a PC-mild solution provided

$$
\xi+2 \eta\|\varsigma\|_{L^{1}\left(J, \mathbb{R}^{+}\right)}<1,
$$

where $\xi=\sum_{i=1}^{i=m} \xi_{i}$.

Moreover, if additionally $E$ is reflexive and there is a $c>1$, such that $\varphi(c t) \leq c \varphi(t)$, for every $t \in[0, \infty)$ and $t=0$ is a point of uniform convergence for the series $\sum_{n=1}^{\infty} \varphi^{n}(t)$, then (3) is generalized Ulam-Hyers stable. 
Proof From $\left(H_{5}\right)$ and $\left(H_{8}\right)$, for any $x \in \operatorname{PC}(J, E)$, the set $S_{F(\cdot, x(\cdot))}^{p}$ is non-empty. Consider the multifunction map, $R: \mathrm{PC}(J, E) \rightarrow 2^{\mathrm{PC}(, E)}$ defined as follows: for $x \in \mathrm{PC}(J, E), R(x)$ is the set of all functions $y \in R(x)$ given by (10). We show that $R$ satisfies the assumptions of Lemma 4.11, that is, $R$ is a $\varphi$-contraction.

Note from $\left(H_{8}\right)$, for every $n \geq 1$, and for a.e. $t \in J$,

$$
\begin{aligned}
\|F(t, x)\| & =h(F(t, x(t)),\{0\}) \\
& \leq h(F(t, x(t)), F(t, 0))+h(F(t, 0),\{0\}) \\
& \leq \varsigma(t) \varphi(\|x(t)\|)+\varsigma(t) \\
& \leq \varsigma(t)\left(1+\varphi\left(\|x\|_{\mathrm{PC}(J, E)}\right)\right) .
\end{aligned}
$$

Moreover, we know that $R$ is closed valued.

Now we show that $R$ is a $\varphi$-contraction. Let $x_{1}, x_{2} \in \operatorname{PC}(J, E)$ and $y_{1} \in R\left(x_{1}\right)$. Then there is a $f \in S_{F\left(\cdot, x_{1}(\cdot)\right)}^{p}$ such that, for any $t \in J_{i}, i=0,1, \ldots, m$,

$$
y_{1}(t)=\left\{\begin{array}{l}
x_{0}+\frac{1}{\Gamma(\alpha)} \int_{0}^{t}(t-s)^{\alpha-1} f(s) d s, \quad t \in\left[0, t_{1}\right] \\
g_{i}\left(t, x_{1}\left(t_{i}^{-}\right)\right), \quad t \in\left(t_{i}, s_{i}\right], i=1,2, \ldots, m, \\
g_{i}\left(s_{i}, x_{1}\left(t_{i}^{-}\right)\right)-\frac{1}{\Gamma(\alpha)} \int_{0}^{s_{i}}\left(s_{i}-s\right)^{\alpha-1} f(s) d s \\
\quad+\frac{1}{\Gamma(\alpha)} \int_{0}^{t}(t-s)^{\alpha-1} f(s) d s \\
\quad t \in\left[s_{i}, t_{i+1}\right], i=1,2, \ldots, m .
\end{array}\right.
$$

Next, since $F\left(t, x_{2}(t)\right)$ is compact for any $t \in J$, the set $U(t)=\left\{x \in F\left(t, x_{2}(t)\right): d(f(t), x)=\right.$ $d(f(t), G(t))\}$ is non-empty. From Lemma 2.9, there is a measurable function $h: J \rightarrow E$ such that $h(t) \in F\left(t, x_{2}(t)\right)$, a.e. and

$$
\|f(t)-h(t)\|=d\left(f(t), F\left(t, x_{2}(t)\right)\right), \quad \text { for a.e. } t \in J .
$$

Observe from $\left(H_{8}\right)$ (i) that we have

$$
h\left(F\left(t, x_{2}(t)\right), F\left(t, x_{1}(t)\right)\right) \leq \varsigma(t) \varphi\left(\left\|x_{2}(t)-x_{1}(t)\right\|\right), \quad \text { for a.e. } t \in J .
$$

Then $h \in S_{F\left(\cdot, x_{2}(\cdot)\right)}^{p}$ with

$$
\|h(t)-f(t)\| \leq \varsigma(t) \varphi\left(\left\|x_{2}(t)-x_{1}(t)\right\|\right), \quad \text { a.e. } t \in J .
$$

Let

$$
y_{2}(t)=\left\{\begin{array}{l}
x_{0}+\frac{1}{\Gamma(\alpha)} \int_{0}^{t}(t-s)^{\alpha-1} h(s) d s, \quad t \in\left[0, t_{1}\right], \\
g_{i}\left(t, x_{2}\left(t_{i}^{-}\right)\right), \quad t \in\left(t_{i}, s_{i}\right], i=1,2, \ldots, m, \\
g_{i}\left(s_{i}, x_{2}\left(t_{i}^{-}\right)\right)-\frac{1}{\Gamma(\alpha)} \int_{0}^{s_{i}}\left(s_{i}-s\right)^{\alpha-1} h(s) d s \\
\quad+\frac{1}{\Gamma(\alpha)} \int_{0}^{t}(t-s)^{\alpha-1} h(s) d s, \\
\quad t \in\left[s_{i}, t_{i+1}\right], i=1,2, \ldots, m .
\end{array}\right.
$$


Now $y_{2} \in R\left(x_{2}\right)$ and if $t \in\left[0, t_{1}\right]$ we get from (39), (40), (41) and Hölder's inequality

$$
\begin{aligned}
\left\|y_{2}(t)-y_{1}(t)\right\| & \leq \frac{1}{\Gamma(\alpha)} \int_{0}^{t}(t-s)^{\alpha-1}\|h(s)-f(s)\| d s \\
& \leq \frac{1}{\Gamma(\alpha)} \varphi\left(\left\|x_{1}-x_{2}\right\|_{\mathrm{PC}(J, E)}\right) \int_{0}^{t}(t-s)^{\alpha-1} \varsigma(s) d s \\
& \leq \varphi\left(\left\|x_{1}-x_{2}\right\|_{\mathrm{PC}(J, E)}\right) \eta\|\varsigma\|_{L^{p}\left(J, \mathbb{R}^{+}\right) .}
\end{aligned}
$$

Similarly, for $t \in\left(t_{i} s_{i}\right], i=1,2, \ldots, m$, using (39), (40), (41) again via $\left(H_{7}\right)$, one has

$$
\begin{aligned}
\left\|y_{2}(t)-y_{1}(t)\right\| & \leq\left\|g_{i}\left(s_{i}, x_{1}\left(t_{i}^{-}\right)\right)-g_{i}\left(s_{i}, x_{2}\left(t_{i}^{-}\right)\right)\right\| \\
& \leq \xi_{i} \varphi\left(\left\|x_{1}\left(t_{i}^{-}\right)-x_{2}\left(t_{i}^{-}\right)\right\|\right) \\
& \leq \xi_{i} \varphi\left(\left\|x_{1}-x_{2}\right\|_{\mathrm{PC}(J, E)}\right) .
\end{aligned}
$$

Next, for $t \in\left[s_{i} t_{i+1}\right], i=1,2, \ldots, m$, we get

$$
\begin{aligned}
\left\|y_{2}(t)-y_{1}(t)\right\| \leq & \left\|g_{i}\left(t, x_{1}\left(t_{i}^{-}\right)\right)-g_{i}\left(t, x_{2}\left(t_{i}^{-}\right)\right)\right\| \\
& +\frac{1}{\Gamma(\alpha)} \int_{0}^{s_{i}}\left(s_{i}-s\right)^{\alpha-1}\|h(s)-f(s)\| d s \\
& +\frac{1}{\Gamma(\alpha)} \int_{0}^{t}(t-s)^{\alpha-1}\|h(s)-f(s)\| d s \\
\leq & \xi_{i} \varphi\left(\left\|x_{1}-x_{2}\right\|_{\mathrm{PC}(J, E)}\right) \\
& +\frac{1}{\Gamma(\alpha)} \varphi\left(\left\|x_{1}-x_{2}\right\|_{\mathrm{PC}(J, E)}\right) \int_{0}^{s_{i}}\left(s_{i}-s\right)^{\alpha-1} \varsigma(s) d s \\
& +\frac{1}{\Gamma(\alpha)} \varphi\left(\left\|x_{1}-x_{2}\right\|_{\mathrm{PC}(J, E)}\right) \int_{0}^{t}(t-s)^{\alpha-1} \varsigma(s) d s \\
\leq & \xi_{i} \varphi\left(\left\|x_{1}-x_{2}\right\|_{\mathrm{PC}(J, E)}\right)+2 \varphi\left(\left\|x_{1}-x_{2}\right\|_{\mathrm{PC}(J, E)) \eta\left\|_{S}\right\|_{L^{p}\left(J, \mathbb{R}^{+}\right)}}^{\leq}\right. \\
\leq & \left(\xi+2 \eta\left\|_{S}\right\|_{L^{p}\left(J, \mathbb{R}^{+}\right)}\right) \varphi\left(\left\|x_{1}-x_{2}\right\|_{\mathrm{PC}(J, E)}\right) .
\end{aligned}
$$

By interchanging the role of $y_{2}$ and $y_{1}$ we obtain from (38) and (42), (43), (44),

$$
\left\|R\left(x_{2}\right)-R\left(x_{1}\right)\right\|_{\mathrm{PC}(J, E)}<\varphi\left(\left\|x_{1}-x_{2}\right\|_{\mathrm{PC}(J, E)}\right) .
$$

Therefore, $R$ is a $\varphi$-contraction and thus by Lemma 4.11, $R$ has a fixed point which is a PC-mild solution for (3).

Next we show that (3) is generalized Ulam-Hyers stable.

Let $\epsilon>0$ and $y \in Z$ such that

$$
\left\{\begin{array}{l}
d\left({ }^{c} D_{0, t}^{\alpha} y(t), F(t, y(t))\right) \leq \epsilon, \quad \text { a.e. } t \in\left(s_{i}, t_{i+1}\right], i=0,1, \ldots, m, \\
\left\|y(t)-g_{i}\left(t, y\left(t_{i}^{-}\right)\right)\right\| \leq \epsilon, \quad t \in\left(t_{i}, s_{i}\right], i=1, \ldots, m, \\
\left\|y\left(t_{i}^{+}\right)-g_{i}\left(t_{i}, y\left(t_{i}^{-}\right)\right)\right\| \leq \epsilon, \quad i=1, \ldots, m .
\end{array}\right.
$$


According to Lemma 2.9, there is a $f \in S_{F(\cdot, y(\cdot))}^{p}$ such that

$$
\left\|{ }^{c} D_{0, t}^{\alpha} y(t)-f(t)\right\|=d\left({ }^{c} D_{0, t}^{\alpha} y(t), F(t, y(t))\right), \quad \text { a.e. } t \in\left(s_{i}, t_{i+1}\right], i=0,1, \ldots, m \text {. }
$$

Then

$$
\left\{\begin{array}{l}
\left\|{ }^{c} D_{0, t}^{\alpha} y(t)-f(t)\right\| \leq \epsilon, \quad \text { a.e. } t \in\left(s_{i}, t_{i+1}\right], i=0,1, \ldots, m, \\
\left\|y(t)-g_{i}\left(t, y\left(t_{i}^{-}\right)\right)\right\| \leq \epsilon, \quad t \in\left(t_{i}, s_{i}\right], i=1, \ldots, m, \\
\left\|y\left(t_{i}^{+}\right)-g_{i}\left(t_{i}, y\left(t_{i}^{-}\right)\right)\right\| \leq \epsilon, \quad i=1, \ldots, m,
\end{array}\right.
$$

which means that

$$
\left\{\begin{array}{l}
{ }^{c} D_{0, t}^{\alpha} y(t)=f(t)+\gamma(t), \quad \text { a.e. } t \in\left(s_{i}, t_{i+1}\right], i=0,1, \ldots, m, \\
y(t)=g_{i}\left(t, y\left(t_{i}^{-}\right)\right)+\gamma(t), \quad t \in\left(t_{i}, s_{i}\right], i=1, \ldots, m, \\
y\left(t_{i}^{+}\right)=g_{i}\left(t_{i}, y\left(t_{i}^{-}\right)\right)+\gamma(t), \quad i=1, \ldots, m,
\end{array}\right.
$$

where $\gamma \in \operatorname{PC}(J, E) \bigcap_{i=0}^{i=m} C^{1}\left(\left(s_{i}, t_{i+1}\right), \mathbb{R}^{+}\right)$and $|\gamma(t)| \leq \epsilon, \forall t \in J$.

Therefore, from Lemma 2.7, one obtains

$$
y(t)=\left\{\begin{array}{l}
y(0)+\frac{1}{\Gamma(\alpha)} \int_{0}^{t}(t-s)^{\alpha-1}(f(s)+\gamma(s)) d s, \quad t \in\left[0, t_{1}\right], \\
g_{i}\left(t, y\left(t_{i}^{-}\right)\right)+\gamma(t), \quad t \in\left(t_{i}, s_{i}\right], i=1, \ldots, m \\
g_{i}\left(s_{i}, y\left(t_{i}^{-}\right)\right)-\frac{1}{\Gamma(\alpha)} \int_{0}^{s_{i}}\left(s_{i}-s\right)^{\alpha-1}(f(s)+\gamma(s)) d s \\
\quad \quad+\frac{1}{\Gamma(\alpha)} \int_{0}^{t}(t-s)^{\alpha-1}(f(s)+\gamma(s)) d s, \quad t \in\left[s_{i}, t_{i+1}\right], i=1,2, \ldots, m .
\end{array}\right.
$$

Next, let $z \in \operatorname{PC}(J, E)$ be defined by

$$
z(t)=\left\{\begin{array}{l}
y(0)+\frac{1}{\Gamma(\alpha)} \int_{0}^{t}(t-s)^{\alpha-1} f(s) d s, \quad t \in\left[0, t_{1}\right] \\
g_{i}\left(t, y\left(t_{i}^{-}\right)\right), \quad t \in\left(t_{i}, s_{i}\right], i=1,2, \ldots, m \\
g_{i}\left(s_{i}, y\left(t_{i}^{-}\right)\right)-\frac{1}{\Gamma(\alpha)} \int_{0}^{s_{i}}\left(s_{i}-s\right)^{\alpha-1} f(s) d s \\
\quad+\frac{1}{\Gamma(\alpha)} \int_{0}^{t}(t-s)^{\alpha-1} f(s) d s, \quad t \in\left[s_{i}, t_{i+1}\right], i=1,2, \ldots, m
\end{array}\right.
$$

Observing that $z \in R(y)$ and from (45) and (46) we get

$$
\|y-z\|_{\mathrm{PC}(J, E)} \leq \frac{2 \epsilon b^{\alpha}}{\Gamma(\alpha+1)}+\epsilon
$$

Now, from Lemma 4.12, $R$ is a $\Psi$-MWPO with $\Psi(t)=t+\sum_{n=1}^{\infty} \varphi^{n}(t)$. Thus, the function $R^{\infty}: \operatorname{Graph}(R) \rightarrow \operatorname{Fix}(R)$ is well defined and

$$
\left\|y-R^{\infty}(y, z)\right\|_{\mathrm{PC}(J, E)} \leq \Psi\left(\|y-z\|_{\mathrm{PC}(J, E)}\right)
$$

Put $x=R^{\infty}(y, z)$. Then $x \in R(x)$ and from (47) and (48) we have

$$
\|x(t)-y(t)\| \leq\|y-x\|_{\mathrm{PC}(J, E)} \leq \Psi\left(\|y-z\|_{\mathrm{PC}(J, E)}\right)=\Psi\left(\frac{2 \epsilon b^{\alpha}}{\Gamma(\alpha+1)}+\epsilon\right):=\theta(\epsilon),
$$

where $\theta(t)=\Psi\left(\frac{2 t b^{\alpha}}{\Gamma(\alpha+1)}+t\right)$. 
Since $\Psi$ is increasing, continuous at 0 and $\Psi(0)=0$, the function $\theta$ is increasing, continuous at $t=0$ and $\theta(0)=0$. Consequently, (3) is generalized Ulam-Hyers stable.

\section{Examples}

In this section, we give examples to illustrate our results. Set $J=[0,1]$.

Example 5.1 Let $K$ be a non-empty closed subset of a compact separable Banach space $E$. Let $F: J \times E \rightarrow P_{c k}(E)$ be a multivalued function defined by

$$
F(t, x)=\frac{e^{-\gamma t}\|x\|}{\lambda(1+\|x\|)} K
$$

where $\gamma \in(1, \infty)$ and $\lambda$ is a constant such that $\sup \{\|z\|: z \in K\} \leq \lambda$. Clearly for every $x \in E, t \rightarrow F(t, x)$ is measurable. Moreover, for any $x \in E$ and any $t \in J$, we have

$$
h(F(t, x), F(t, y)) \leq e^{-\gamma t}\left|\frac{\|x\|}{1+\|x\|}-\frac{\|y\|}{1+\|y\|}\right| \leq e^{-\gamma t}\|x-y\| .
$$

For a.e. $t \in J, x \rightarrow F(t, x)$ is upper semicontinuous, i.e., $\left(H_{1}\right)$ is satisfied.

For every bounded subset $D \subseteq E, \chi(F(t, D)) \leq \beta(t) \chi(D)$ for a.e. $t \in J$ holds with $\beta(t)=$ $e^{-\gamma t}$. Also, for any $(t, x) \in J \times E$,

$$
\|F(t, x)\| \leq e^{-\gamma t} \leq e^{-\gamma t}(1+\|x\|)
$$

Then $\left(H_{2}\right)$ is satisfied with $\varphi(t)=e^{-\gamma t}$ and $\Omega(t)=t+1$.

Now, for any $i=1,2, \ldots, m$, let $g_{i}:\left[t_{i}, s_{i}\right] \times E \rightarrow E$, be defined by

$$
g_{i}(t, x)=\xi_{i} x,
$$

where $\xi_{i}, i=1,2, \ldots, m$, is a positive constant. Obviously $g_{i}$ is continuous and since $E$ is compact $g_{i}$ is a compact map. Moreover, $\left\|g_{i}(t, x)\right\| \leq \xi_{i}\|x\|$. Thus $\left(\mathrm{H}_{4}\right)$ is satisfied. From Theorem 3.1, problem (3) has a PC-mild solution, where $F$ and $g_{i}$ are given by (49) and (50) provided that

$$
8 \eta\|\beta\|_{L^{p}(J, E)}<1,
$$

and there is a $r>0$ such that

$$
\left\|x_{0}\right\|+\sum_{i=1}^{m} \xi_{i} r+2(r+1)\|\varphi\|_{L^{1}(J, E)}<r
$$

Note that (51) is equivalent to

$$
\frac{8}{\Gamma(\alpha)}\left(\frac{p-1}{\alpha p-1}\right)^{\frac{p-1}{p}}\left(\frac{1}{\gamma p}-\frac{e^{-\gamma p}}{-\gamma p}\right)<1,
$$

and this inequality will be satisfied if

$$
\frac{8}{\gamma p \Gamma(\alpha)}\left(\frac{p-1}{\alpha p-1}\right)^{\frac{p-1}{p}}<1
$$


Similarly (52) will be satisfied if

$$
\left\|x_{0}\right\|+\sum_{i=1}^{m} \xi_{i} r+\frac{2(r+1)}{\gamma}<r
$$

which is equivalent to

$$
\left\|x_{0}\right\|+\frac{2}{\gamma}<r\left(1-\left(\sum_{i=1}^{m} \xi_{i}+\frac{2}{\gamma}\right)\right) \text {. }
$$

So, by choosing $\gamma$ large enough one can arrive at (53) and choosing $\xi_{i}$ such that $\sum_{i=1}^{m} \xi_{i}+$ $\frac{2}{\gamma}<1$. Then, by applying Theorem 3.1, problem (3) has a PC-mild solution. Further, by applying Theorem 3.2 the set of solutions of (3) is a non-empty compact set.

Example 5.2 Set $E=\left\{x=\left\{x_{n}\right\}_{n \in \mathbb{Z}}: x_{n} \in \mathbb{R}, \lim _{n \rightarrow \pm \infty} x_{n}=0\right\}$ with the norm $\|x\|=$ $\sup _{n \in \mathbb{Z}}\left|x_{n}\right|$. Then $E$ is a separable Banach space.

Let $F: J \times E \rightarrow 2^{E}$ be a multifunction defined by

$$
F(t, x)=\left\{f_{n}\left(t, x_{n-1}, x_{n}, x_{n+1}\right)\right\}_{n \in \mathbb{Z}}
$$

where for any $n \in \mathbb{Z}, f_{n}: J \times \mathbb{R}^{3} \rightarrow 2^{\mathbb{R}}$ is a multifunction defined as

$$
f_{n}(t, \mu, \eta, \sigma)=a_{1} \frac{\cos 2 \pi t}{|n|+1}+\left[-a_{2} \eta, a_{2} \eta\right]+a_{3} \mu+a_{4} \sigma
$$

where $a_{1}, a_{2}, a_{3}$ and $a_{4}$ are constants. It is easy to see that $\left(H_{5}\right)$ is satisfied. Moreover, for any $(t, x) \in J \times E$,

$$
\begin{aligned}
\|F(t, x)\| & \leq\left|a_{1}\right|+\left|a_{2}\right|\left|x_{n}\right|+\left|a_{3}\right|\left|x_{n-1}\right|+\left|a_{4}\right|\left|x_{n+1}\right| \\
& \leq\left|a_{1}\right|+3 A\|x\| \\
& \leq 3 A(1+\|x\|),
\end{aligned}
$$

where $A=\max \left\{\left|a_{1}\right|,\left|a_{2}\right|,\left|a_{3}\right|,\left|a_{4}\right|\right\}$. Thus condition $\left(H_{6}\right)$ (ii) is satisfied with $\zeta(\cdot)=3 A$. Next, let $t \in J, x, y \in E, u \in F(t, x)$ and $v \in F(t, y)$. Then

$$
u=\left(a_{1} \frac{\cos 2 \pi t}{|n|+1}+\lambda_{n} x_{n}+a_{3} x_{n-1}+a_{4} x_{n+1}\right)_{n \in \mathbb{Z}}
$$

and

$$
v=\left(a_{1} \frac{\cos 2 \pi t}{|n|+1}+\mu_{n} y_{n}+a_{3} y_{n-1}+a_{4} y_{n+1}\right)_{n \in \mathbb{Z}},
$$

where $\left|\lambda_{n}\right| \leq\left|a_{2}\right|$ and $\left|\mu_{n}\right| \leq\left|a_{2}\right|$. Then

$$
\|u-v\|_{E}=\sup _{n \in \mathbb{Z}}\left\|u_{n}-v_{n}\right\| \leq 3 A\|x-y\|
$$


which means that

$$
h(F(t, x), F(t, y)) \leq 3 A\|x-y\| .
$$

Thus $\left(H_{6}\right)(\mathrm{i})$ is satisfied.

Now, for any $i=1,2, \ldots, m$, let $g_{i}:\left[t_{i}, s_{i}\right] \times E \rightarrow E$ be defined by (50). Now $\left(H_{7}\right)$ is satisfied. Then, from Theorem 3.3, problem (3) has a PC-mild solution.

Example 5.3 Let $K$ be a non-empty convex compact subset of a separable reflexive Banach space $E$. Let $F: J \times E \rightarrow P_{c k}(E)$ be a multivalued function defined by

$$
F(t, x)=\frac{e^{-\beta t}\|x\|}{\lambda \sigma(1+\|x\|)} K,
$$

where $\beta, \sigma \in(1, \infty)$ and $\lambda$ is a constant such that $\sup \{\|z\|: z \in K\} \leq \lambda$. The multivalued function $F$ satisfies condition $\left(H_{5}\right)$. Moreover, for any $x \in E$ and any $t \in J$, we have

$$
h(F(t, x), F(t, y)) \leq \frac{e^{-\beta t}}{\sigma}\left|\frac{\|x\|}{1+\|x\|}-\frac{\|y\|}{1+\|y\|}\right| \leq \frac{e^{-\beta t}}{\sigma}\|x-y\| .
$$

Then $\left(H_{8}\right)$ (i) holds with $\zeta(t)=e^{-\beta t}, t \in J$ and $\varphi(t)=\frac{t}{\sigma}, t \in[0, \infty)$. Note that $\varphi$ is strictly comparison. Clearly $\left(H_{8}\right)$ (ii) holds because $\|F(t, 0)\|=0, t \in J$.

Now, for any $i=1,2, \ldots, m$, let $g_{i}:\left[t_{i}, s_{i}\right] \times E \rightarrow E$ be defined by (50). Now $\left(H_{9}\right)$ is satisfied. Then, from Theorem 4.15 problem (3) has a PC-mild solution provided that (38) holds. The inequality (38) is equivalent to

$$
\xi+\frac{2}{\Gamma(\alpha)}\left(\frac{p-1}{\alpha p-1}\right)^{\frac{p-1}{p}}\left(\frac{1}{\beta}-\frac{1}{\beta e^{\beta}}\right)<1,
$$

and the above inequality will be satisfied if

$$
\xi+\frac{2}{\beta \Gamma(\alpha)}\left(\frac{p-1}{\alpha p-1}\right)^{\frac{p-1}{p}}<1 .
$$

By choosing $\xi_{i}$ sufficient small and $\beta$ large enough one can arrive at (54).

Observe that, for any $c \in \mathbb{R}, \varphi(c t)=c \varphi(t), t \in[0, \infty)$ and $t=0$ is a point of uniform convergence for the series $\sum_{n=1}^{\infty} \varphi^{n}(t)=\sum_{n=1}^{\infty} \frac{t}{\sigma^{n}}$. Then, from Theorem 4.15 problem (3) is generalized Ulam-Hyers stable.

Competing interests

The authors declare that they have no competing interests.

Authors' contributions

JW, AGI and DO contributed to Sections 1, 2, 3, 4 and 5. YZ contributed to Sections 1 and 5. All authors read and approved the final manuscript.

\section{Author details}

'Department of Mathematics, Guizhou University, Guiyang, Guizhou 550025, P.R. China. ²Department of Mathematical, Faculty of Science, King Faisal University, Al-Ahasa, 31982, Saudi Arabia. ${ }^{3}$ School of Mathematics, Statistics and Applied Mathematics, National University of Ireland, Galway, Ireland. ${ }^{4}$ Faculty of Mathematics and Computational Science, Xiangtan University, Hunan, 411105, P.R. China. ${ }^{5}$ Nonlinear Analysis and Applied Mathematics (NAAM) Research Group, Faculty of Science, King Abdulaziz University, P.O. Box 80203, Jeddah, 21589, Saudi Arabia. 


\section{Publisher's Note}

Springer Nature remains neutral with regard to jurisdictional claims in published maps and institutional affiliations.

\section{Received: 4 July 2017 Accepted: 26 August 2017 Published online: 15 September 2017}

\section{References}

1. Ahmad, B, Alsaedi, A, Kirane, M: Nonexistence results for the Cauchy problem of time fractional nonlinear systems of thermoelasticity. Math. Methods Appl. Sci. 40, 4272-4279 (2017)

2. Ahmad, B, Alsaedi, A, Kirane, M, Tapdigoglu, RG: An inverse problem for space and time fractional evolution equations with an involution perturbation. Quaest. Math. 40(2), 151-160 (2017)

3. Baleanu, D, Sayevand, K: Performance evaluation of matched asymptotic expansions for fractional differential equations with multi-order. Bull. Math. Soc. Sci. Math. Roum. 59, 3-18 (2017)

4. Chang, YK, Nieto, JJ: Some new existence results for fractional differential inclusions with boundary conditions. Math Comput. Model. 49, 605-609 (2009)

5. El-Sayed, AMA, Ibrahim, AG: Multivalued differential inclusions. Appl. Math. Comput. 68, 15-25 (1995)

6. Glocke, WH, Nonnemacher, TF: A fractional calculus approach of self-similar protein dynamics. Biophys. J. 68, 46-53 (1995)

7. Hilfer, R: Applications of Fractional Calculus in Physics. World Scientific, Singapore (1999)

8. Zhou, Y: Fractional Evolution Equations and Inclusions: Analysis and Control. Academic Press, San Diego (2016)

9. Chen, $P, L i, Y$ : Existence of mild solutions for fractional evolution equations with mixed monotone nonlocal conditions. Z. Angew. Math. Phys. 65, 711-728 (2014)

10. Li, K, Peng, J: Controllability of fractional neutral stochastic functional differential systems. Z. Angew. Math. Phys. 65, 941-959 (2014)

11. Liu, Z, Zeng, B: Existence and controllability for fractional evolution inclusions of Clarke's subdifferential type. Appl. Math. Comput. 257, 178-189 (2015)

12. Liu, Z, Li, X: On the exact controllability of impulsive fractional semilinear functional differential inclusions. Asian J. Control 17, 1857-1865 (2015)

13. Wang, J, Zhou, Y, Wei, W: Fractional Schrödinger equations with potential and optimal controls. Nonlinear Anal., Real World Appl. 13, 2755-2766 (2012)

14. Wang, J, Fečkan, M, Zhou, Y: Center stable manifold for planar fractional damped equations. Appl. Comput. Math. 296, 257-269 (2017)

15. Zhou, Y, Ahmad, B, Alsaedi, A: Existence of nonoscillatory solutions for fractional neutral differential equations. Appl. Math. Lett. 72, 70-74 (2017)

16. Zhou, Y, Peng, L: Weak solutions of the time-fractional Navier-Stokes equations and optimal control. Comput. Math. Appl. 73, 1016-1027 (2017)

17. Zhou, Y, Peng, L: On the time-fractional Navier-Stokes equations. Comput. Math. Appl. 73, 874-891 (2017)

18. Zhou, Y, Vijayakumar, V, Murugesu, R: Controllability for fractional evolution inclusions without compactness. Evol. Equ. Control Theory 4, 507-524 (2015)

19. Zhou, Y, Zhang, L: Existence and multiplicity results of homoclinic solutions for fractional Hamiltonian systems. Comput. Math. Appl. 73, 1325-1345 (2017)

20. Zhou, Y, Peng, L, Ahmad, B, Alsaedi, A: Topological properties of solution sets of fractional stochastic evolution inclusions. Adv. Differ. Equ. 2017(1), 90 (2017)

21. Benchohra, M, Henderson, J, Ntouyas, SK: Impulsive Differential Equations and Inclusions. Hindawi Publ. Corp., New York (2006)

22. d'Onofrio, A: On pulse vaccination strategy in the SIR epidemic model with vertical transmission. Appl. Math. Lett. 18, 729-732 (2005)

23. Samoilenko, AM, Perestyuk, NA, Chapovsky, Y: Impulsive Differential Equations. World Scientific, Singapore (1995)

24. Wang, J, Fečkan, M, Zhou, Y: A survey on impulsive fractional differential equations. Fract. Calc. Appl. Anal. 19, 806-831 (2016)

25. Myshkis, AD, Samoilenko, AM: Sytems with impulsive at fixed moments of time. Mat. Sb. 74, 202-208 (1967)

26. Hernándaz, E, O'Regan, D: On a new class of abstract impulsive differential equation. Proc. Am. Math. Soc. 141 1641-1649 (2013)

27. Fan, Z: Impulsive problems for semilinear differential equations with nonlocal conditions. Nonlinear Anal. 72 1104-1109 (2010)

28. Fečkan, M, Zhou, Y, Wang, J: On the concept and existence of solution for impulsive fractional differential equations. Commun. Nonlinear Sci. Numer. Simul. 17, 3050-3060 (2012)

29. Henderson, J, Ouahab, A: Impulsive differential inclusions with fractional order. Comput. Math. Appl. 59, 1191-1226 (2010)

30. Wang, J, Fečkan, M, Zhou, Y: On the new concept of solutions and existence results for impulsive fractional evolutions. Dyn. Partial Differ. Equ. 8, 345-361 (2011)

31. Wang, J, Zhang, Y: On the concept and existence of solutions for fractional impulsive systems with Hadamard derivatives. Appl. Math. Lett. 39, 85-90 (2015)

32. Pierri, $M, O$ 'Regan, D, Rolnik, V: Existence of solutions for semi-linear abstract differential equations with not instantaneous impulses. Appl. Math. Comput. 219, 6743-6749 (2013)

33. Wang, J, Fečkan, M: A general class of impulsive evolution equations. Topol. Methods Nonlinear Anal. 46, 915-933 (2015)

34. Abbas, S, Benchohra, M: Uniqueness and Ulam stabilities results for partial fractional differential equations with not instantaneous impulses. Appl. Math. Comput. 257, 190-198 (2015)

35. Agarwal, R, O'Regan, D, Hristova, S: Stability by Lyapunov like functions of nonlinear differential equations with non-instantaneous impulses. J. Appl. Math. Comput. 53, 147-168 (2017)

36. Gautam, GR, Dabas, J: Mild solutions for class of neutral fractional functional differential equations with not instantaneous impulses. Appl. Math. Comput. 259, 480-489 (2015) 
37. Hegyi, B, Jung, SM: On the stability of Laplace's equation. Appl. Math. Lett. 26, 549-552 (2013)

38. Hernández, E, Pierri, M, O’Regan, D: On abstract differential equations with non instantaneous impulses. Topol. Methods Nonlinear Anal. 46, 1067-1085 (2015)

39. Hyers, DH, Isac, G, Rassias, TM: Stability of Functional Equations in Several Variables. Springer, Media (2012)

40. Pierri, M, Henríquez, HR, Prokczyk, A: Global solutions for abstract differential equations with non-instantaneous impulses. Mediterr. J. Math. 113, 1685-1708 (2016)

41. Wang, J, Ibrahim, AG, Fečkan, M: Nonlocal impulsive fractional semilinear differential inclusions with fractional sectorial operators in Banach spaces. Appl. Math. Comput. 257, 103-118 (2015)

42. Ulam, SM: A Collection of Mathematical Problems. Interscience Publishers, New York (1968)

43. Cardinali, T, Rubbioni, P: Impulsive mild solution for semilinear differential inclusions with nonlocal conditions in Banach spaces. Nonlinear Anal. 75, 871-879 (2012)

44. Jung, SM: Hyers-Ulam-Rassias Stability of Functional Equations in Nonlinear Analysis. Springer, New York (2011)

45. Li, Y, Huang, J: Hyers-Ulam stability of linear second-order differential equations in complex Banach spaces. Electron. J. Differ. Equ. 2013(50), 184 (2013)

46. Lungu, N, Popa, D: Hyers-Ulam stability of a first order partial differential equation. J. Math. Anal. Appl. 385, 86-91 (2012)

47. Petru, TP, Pertuselşel, A, Yao, JC: Ulam-Hyers stability for operational equations and inclusions via nonself operators. Taiwan. J. Math. 15, 2195-2212 (2011)

48. Parthasarathy, C: Existence and Hyers-Ulam stability of nonlinear impulsive differential equations with nonlocal condotions. Electron. J. Math. Anal. Appl. 4, 106-115 (2016)

49. Rassias, TM: On the stability of linear mappings in Banach spaces. Proc. Am. Math. Soc. 72, 297-300 (1978)

50. Rus, IA: Generalized Contractions and Applications. Cluj University Press, Cluj-Napoca (2001)

51. Aubin, JP, Frankoeska, H: Set-Valued Analysis. Birkhäuser, Basel (1990)

52. Bajlekova, E: Fractional evolution equations in Banach spaces, Ph.D. thesis, Eindhoven University of Technology (2001)

53. Kilbas, AA, Srivastava, HM, Trujillo, JJ: Theory and Applications of Fractional Differential Equations. North Holland Mathematics Studies. Elsevier, Amsterdam (2006)

54. Castaing, C, Valadier, M: Convex Analysis and Measurable Multifunctions. Springer, Berlin (1977)

55. Aliprantis, CD, Border, K: Infinite Dimensional Analysis: A Hitchhiker's Guide. Springer, Media (2006)

56. Kamenskii, M, Obukhowskii, V, Zecca, P: Condensing Multivalued Maps and Semilinear Differential Inclusions in Banach Spaces. de Gruyter, Berlin (2001)

57. Covitz, H, Nadler, SB: Multivalued contraction mapping in generalized metric space. Isr. J. Math. 8, 5-11 (1970)

58. Bothe, D: Multivalued perturbation of $m$-accretive differential inclusions. Isr. J. Math. 108, 109-138 (1998)

59. Bader, R, Kamenskii, M, Obukhowskii, V: On some class of operator inclusions with lower semicontinuous nonlinearity. Topol. Methods Nonlinear Anal. 17, 143-156 (2001)

60. Pertuselşel, A: Multivalued weakly Picard operators and applications. Sci. Math. Jpn. 95, 167-202 (2004)

61. Rus, IA, Petruşel, A, Sîntǎmǎrian, A: Data dependence of the fixed point set of some multivalued weakly Picard operators. Nonlinear Anal. 52, 1947-1959 (2003)

62. Wȩgrzyk, R: Fixed Point Theorem for Multifunctions and Their Applications to Functional Equations. Instytut Matematyczny Polskiej Akademi Nauk, Warszawa (1982)

63. Lazăr, VL: Fixed point theory for multi-valued $\varphi$-contraction. Fixed Point Theory Appl. 2011, 50 (2011)

\section{Submit your manuscript to a SpringerOpen ${ }^{\circ}$ journal and benefit from:}

- Convenient online submission

- Rigorous peer review

- Open access: articles freely available online

- High visibility within the field

- Retaining the copyright to your article

Submit your next manuscript at $\boldsymbol{s p r i n g e r o p e n . c o m ~}$ 